\title{
59 A RAPIDLY FATAL CASE OF SEVERE FALCIPURUM MALARIA COMPLICATED WITH HIGH-LEVEL METABOLIC ACIDOSIS
}

\author{
Yuriko SaITO ${ }^{1}$, Mikio TAKamori ${ }^{1}$ And Mikio Kimura ${ }^{2}$ \\ Department of Internal Medicine, Tokyo Kousei Nenkin Hospital ${ }^{1}$ and \\ Department of Infectious Diseases and Applied Immunology, \\ Institute of Medical Science, The University of Tokyo ${ }^{2}$
}

\begin{abstract}
A 67-year-old male was admitted presenting with consciousness disturbance (JCS, III-200) after completing a 12-day tour to east Africa without malaria chemoprophylaxis. When he visited the hospital one day prior to admission complaining fever and slight sore throat, he did not mention the travel history. Soon after his travel history was revealed, blood films were prepared which showed abundant ring forms mixed with a small number of trophozoites and schizonts of Plasmodium falciparum, with the parasitemia of $26 \%$. Despite intravenous quinine infusion, first that of loading dose, his consciousness state (JCS, III-300), renal and hepatic functions and anemia $(\mathrm{Hb}, 5.8 \mathrm{~g} / \mathrm{d} l$ ) deteriorated progressively. Moreover, metabolic acidosis worsened with
\end{abstract}

the $\mathrm{pH}$ of $6.954, \mathrm{HCO}_{3}{ }^{-}$of $6.1 \mathrm{mmol} / l$ and $\mathrm{BE}$ of $16.1 \mathrm{mmol} / \mathrm{l}$ by arterial blood gas analysis, although he received a large volume of sodium bicarbonate solution. The patient died on the 4th day of his illness.

According to the literature, it is suggested that the treatment of metabolic acidosis in severe falciparum malaria with sodium bicarbonate could sometimes be harmful, since it can result in sodium overload which may then precipitate pulmonary edema/ARDS. However, alternative treatment regimens have not yet been established. Future investigations on the etiology and the proper treatment of metabolic acidosis associated with severe falciparum malaria are strongly needed.

\section{A RESCUED CASE OF COMPLICATED FALCIPARUM MALARIA USING CONTINUOUS HEMODIAFILTRATION (CHDF)}

\author{
Kyoko Kimura ${ }^{1}$, Kaori Nakamura ${ }^{2}$, Yuuichi Hamabe ${ }^{2}$ and Kenji Ohnishi ${ }^{1}$ \\ Department of Infectious Diseases ${ }^{1}$ and Life Support Emergency Center ${ }^{2}$, \\ Tokyo Metropolitan Bokutoh General Hospital
}

A 65 -year-old woman was admitted to the Life Support and Emergency Center in our hospital with cerebral malaria on October 21, 1998. She had traveled in Niger from September 22 to October 6, 1998. She was comatose (Glasgow coma scale, E4V1M1), hyperpyretic, in respiratory distress, and had acidosis and acute renal failure on admission. Her hemoglobin concentration was $8.2 \mathrm{~g} / \mathrm{d} l$ and her platelet count was $56,000 / \mu l$. Blood smears showed ring form of Plasmodium falcipar. $u m$ and a parasitemia level of $12.2 \%$.

An antimalarial chemotherapy with quinine (Quinimax $^{\mathrm{R}} 700 \mathrm{mg}$, div, q $8 \mathrm{hr}, 2$ times plus $350 \mathrm{mg}$ after $8 \mathrm{hr}, 1$ time), mefloquine (1,000 $\mathrm{mg}$, po plus $500 \mathrm{mg}$ after $8 \mathrm{hr}$ ) and artesunate ( $250 \mathrm{mg}$, suppo, q $6 \mathrm{hr}, 6$ times) was performed immediately along with intensive care. But pulmonary edema, acute renal failure, anemia and thrombocytopenia deteriorated and mechanical ventila- tion and continuous hemodiafiltration (CHDF) were induced on her second day of hospitalization. $800 \mathrm{~m} l$ of red blood cell concentrates and 10 units of platelet concentrates were transfused through CHDF. Acidosis was quickly corrected within one day and pulmonary edema, acute renal failure, and her level of consciousness gradually improved. $P$. falciparum had disappeared by her 6th day of hospitalization. She was weaned off mechanical ventilation and CHDF on her 7th day of hospitalization. Three hemodialysis sessions were added at two-day intervals. She recovered almost perfectly after one month of rehabilitation and was discharged on December 12, 1998.

$\mathrm{CHDF}$ is one of the blood purification teqniques which is used for critically ill patients, such as those with multiple organ failure, in the area of emergency and critical care medicine. It has been proved that 
CHDF can not only compensate for renal dysfunction and correct acidosis, electrolyte imbalance, and water balance, but also remove toxic substance, such as cytokines, humoral mediators, lactic acid and improve tissue oxygeneration.

We induced antimalarial drugs to attack the malaria itself and used CHDF to eliminate toxic sub- stances and to manage the overall critically ill situation. This combination was successful and required a minimum amount of blood transfusion, which is much safer than blood exchange. We conclude that CHDF is effective as one of the ancillary treatments of cerebral malaria.

\title{
61 CURRENT SITUATION OF MALARIA CHEMOPROPHYLAXIS AMONG JAPANESE RESIDENTS IN TROPICAL AFRICA
}

\author{
Atsuo Hamada, Eirchi Okuzawa, Yuka Hiroshige and Tetsuo Nishikawa \\ Japan Overseas Health Administration Center, Labor Welfare Cooperation
}

[Objective] In Japan, malaria chemoprophylaxis is not officially recommended for Japanese staying in the endemic area. However, it is supposed that some Japanese have already taken the measure without any official guideline. Therefore, we surveyed a current situation of malaria chemoprophylaxis among Japanese residents in tropical Africa.

[Methods] The survey was carried out in 1994 and 1998 with a self-administered questionnaire. The questionnaire was completed by 129 (in 1994) and 139 (in 1998) Japanese residents in Tanzania, Nigeria, Ghana and Cote D'lvorie (Ave. age: 24.8 yo in 1994 and 35.9 yo in 1998, Ave. period of stay: 31.8 months in 1994 and 30.5 months in 1998).

[Results] Japanese who took malaria chemoprophylaxis was 23.3\% (30) in 1994 and $36.7 \%$ (51) in 1998, suggesting that the ratio in 1998 significantly elevated compared to that in $1994(\mathrm{p}<0.02)$. Regarding to the drug regimen, more than $60 \%$ of Japanese used chloroquine alone in both 1994 and 1998. Users of chloroquine plus proguanil increased in 1998 (23.5\%) compared with that in $1994(3.3 \%)$, although mefloquine users decreased from $16.6 \%$ in 1994 to $12.2 \%$ in 1998 . Failure of chemoprophylaxis was observed in users of chloroquine alone $(16.7 \%)$ and chloroquine plus proguanil $(8.3 \%)$ (data in 1998). Mild adverse reactions such as gastroenteric and neurological symptoms were frequently associated with each regimen especially in mefloquine. [Discussion] Recently, chemoprophylaxis becomes a major preventive measure of malaria among Japanese residents in tropical Africa. It is an urgent need to provide them an official guideline for the chemoprophylaxis in order to carry out the measure correctly.

\section{A FIELD STUDY ON MALARIA PREVALENCE IN SOUTHEASTERN LAOS BY POLYMERASE CHAIN REACTION ASSAY}

\author{
Hiroshi TOMA ${ }^{1}$, Jun KOBAYASHI ${ }^{1,2}$, BOUAKHAM VANNACHON ${ }^{2}$, \\ TAKESHI ARAKaWA ${ }^{1}$ and Yoshiya SaTO ${ }^{1}$ \\ Department of Parasitology, Faculty of Medicine, \\ University of the Ryukyus ${ }^{1}$ and \\ Institute of Malariology, Parasitology and Entomoligy, Lao PDR ${ }^{2}$
}

An active case detection survey for malaria infection by a routine microscopy and polymerase chain reaction (PCR) assay was conducted on the 336 inhabitants in two villages of Khammouane Province in Lao PDR, in July, 1997. The malaria infection was demonstrated in $58(17.3 \%)$ of the subjects by microscopy and in as many as $117(34.8 \%)$ by the PCR assay. The prevalence rate was highest $(50 \%)$ in young villagers aged from 11 to 20 years old, showing that more than $50 \%$ of the positive villagers were occupied by children under 15 years old. The specimens demonstrated to be positive by both methods were frequent in the young 
villagers, suggesting the presence of many latent infections in elderly villagers.

The most abundant etiologic species of malaria parasite was $P$. falciparum $(82.9 \%)$ in these villages. $P$. vivax occupied $31.6 \%$ of the malaria parasites detected by the PCR assay. P. malariae and $P$. ovale infections were also demonstrated in 8 and 6 specimens by the PCR assay, respectively. The PCR assay detected mixed infections with two to four malaria species in 27 specimens $(23.1 \%)$. The results in the present study demonstrated that there are many latent malaria infection with low parasite level among the villagers and the infections with all human malaria species are occurring in the country.

\title{
63 APPROPRIATE TECHNICAL TRANSFER FOR CONTROL PROGRAM OF PARASITIC DISEASES IN DEVELOPING COUNTRIES
}

\author{
Hiroshi OHMAE ${ }^{1}$ AND KAZUO YASURAOKA ${ }^{2}$ \\ Institute of Basic Medical Sciences, University of Tsukuba ${ }^{1}$ and \\ Department of Medical Zoology, School of Medicine, Dokkyo University ${ }^{2}$
}

We investigated appropriate technical tranfer for control program of parasitic diseases in developing countries. Since 1981, we have been cooperating a control program of schistosomiasis japonica in Bohol, the Philippines. And since 1991, we have been cooperating a control program of malaria in Guadalcanal, the Solomon Islands.

After the introduction of selective mass treatment, prevalence of Schistosoma japonicum infections has reduced from $15 \%$ to $5 \%$ in the Philippines. A combination control program for schistosomiasis including selective mass treatment and snail control started in Bohol, in 1986. And this program is supported by a Japanese non governmental organization (NGO). Prevalence of S. japonicum has reduced from $4.9 \%$ in 1984 to $0.1 \%$ in 1992. For evaluation of this control program, an immunological technique which had been transferd from Japan in a cooperation project supported by JICA, was very useful.
In the Solomon Islands, we had a JICA's technical cooperation project for malaria control, from 1992 to 1996. Annual incidence of malaria has reduced from $500 / 1,000$ in 1992 to $200 / 1,000$ in 1996 . As the first step of malaria control program in the Solomon Islands, insectcide-treated bed nets were distributed. After the distribution of insectcide-treated bed nets, joint program with mass blood survey and selective mass treatment was carried out in primary schools. Following the project supported by JICA, this control activity has been supported by a program of Japanese ministry of health and welfare. For evaluation of this control program, a new microscopic technique which had been transferd from Japan in the cooperation project supported by JICA, was used.

For parisitic control program in developing countries, appropriate technical transfer is very important. And combination of Go and NGO projects is very useful to go on or expand control programs.

\section{THE MALARIA MATHEMATICAL MODEL FOR PLASMODIUM VIVAX AND ITS COMPUTER SIMULATION}

\author{
HiROFUMI ISHIKAWA ${ }^{1}$, AKIRA ISHII ${ }^{2}$ AND MAI SHIMIZU ${ }^{3}$ \\ Department of Environmental and Mathematical Sciences, \\ Okayama University ${ }^{1}$, \\ Department of Medical Zoology, Jichi Medical School ${ }^{2}$ and \\ Nippon Telegragh and Telephone West Cooperation ${ }^{3}$
}

To make an estimate of the degree of transmission of Plasmodium vivax malaria, and to estimate the incidence of $P$. vivax when the mass drug administration and/or any anti-malarial measures, such as the distribution of permethrin impregnated bed nets, are carried out, we construct a mathematical model for transmis- 
sion of $P$. vivax, which is formed as the system of nonlinear difference equations, and have carried out various simulations on this model. In addition to direct infection from vectors, the symptom of $P$. vivax is caused by the relapse of a hypnozoite in the liver, and this is a contrast to $P$. falciparum. The patterns of the relapse period are widely distributed around 100 days after the primary infection. We take the cases of relapses into account in our model, which is based on Dietz-Molineaux-Thomas model. The epidemiological parameters are determined by the field data surveyed in the Solomon Islands, 1993.

The simulation carried out shows that in the Solomon Islands, a holoendemic region, about $4-6 \%$ of the population hold hypnozoites in their livers. We cannot expect an efficient transmission blocking in the case that a single dose of primaquine $45 \mathrm{mg}$ is put into practice once a year, which is usually used as the mass drug administration for $P$. falciparum, since the relapse of the hypnozoite restores the prevalence of $P$. vivax before long. In the case of the mass drug administration in which the doses of primaquine $15 \mathrm{mg}$ are iterated for 14 days, the trial will succeed in keeping the prevalence at low level, but it will resurge within a few years. If the mass drug administration is accompanied with vector control diminishing vectorial capacity to $40 \%$, the prevalence of $P$. vivax will be preserved at a low level for a long time.

\title{
65 PLASMODIUM COATNEYI: CYTOADHERENCE OF INFECTED MONKEY ERYTHROCYTES TO HUMAN UMBILICAL VEIN ENDOTHELIAL CELLS AND C32 AMELANOTIC MELANOMA CELLS IN VITRO
}

\author{
Satoru KaWAI ${ }^{1}$, Jun MatSUmoto ${ }^{1}$, MASASHi KirinOKI ${ }^{1}$, \\ MASAMichi AikAWA ${ }^{2}$ AND HaJime MATSUdA ${ }^{1}$ \\ Department of Medical Zoology, Dokkyo University School of Medicine ${ }^{1}$ and \\ Research Institute of Medical Sciences, Tokai University ${ }^{2}$
}

Binding assays with the C32 amelanotic melanoma cells (C32 cells) and human umbilical vein endothelial cells (HUVECs) are commonly used as in vitro models of adherence of $P$. falciparum-infected erythrocytes to endothelial cells. C32 cells express mainly CD36 and little ICAM-1, while HUVECs express ICAM-1, modulated by cytokines such as TNF, but not CD36. In the present study, we have shown that adhesion events in vitro similar to those $P$. falciparum-infected with erythrocytes occur with $P$. coatneyi-infected erythrocytes obtained from Japanese macaques.

$P$. coatneyi-infected erythrocytes were able to attach to both HUVECs and C32 cells. However, the adherent cell number and the number of adherent parasitized red blood cells (PRBCs) differed significantly between HUVECs and C32 cells. Cytoadherence was significantly higher on C32 cells than on HUVECs. Binding of PRBC to HUVECs were observed in 44 cells per 100 cells (44\%), and the mean number of bound PRBC per cell was 1.5, ranging from 1 to 7 . Binding of PRBCs to C32 cells were observed in 84 cells ( $84 \%$ ) per 100 cells, and the mean number of bound PRBC per cell was 12.8, ranging from 1 to 41 . Scanning electron microscopy revealed knob protrusions evenly distributed over the entire surface of adherent PRBC. Higher magnification of the site of attachment revealed that interaction of the PRBCs with cultured cells was mediated by protrusion of knobs.

The specific interactions between host receptors and ligands on monkey erythrocytes infected with $P$. coatneyi have been poorly described. As described for $P$. falciparum, if the parasite antigen as PfEMP1 family are expressed on the surface of $P$. coatneyi-infected erythrocytes, our findings suggest that $\mathrm{CD} 36$ is one of the major host receptors for adherence to endothelial cells. 


\title{
66 EXAMINATION OF PHOSPHOLIPASE A2 IN SERA FROM MALARIA PATIENTS BY ELISA
}

\author{
Kumiko Sato ${ }^{1}$, Shigeyuki Kano ${ }^{2}$, Yoshitsugu Matsumoto 3 , \\ Sornchai LoOAREESUWAN ${ }^{4}$, Masamichi AikaWA ${ }^{5}$ AND Mamoru SUZUKI ${ }^{6}$ \\ Gunma University School of Health Sciences ${ }^{1}$, \\ Research Institute International Medical Center of Japan ${ }^{2}$ \\ School of Agriculture and Life Sciences, The University of Tokyo ${ }^{3}$ \\ Faculty of Tropical Medicine, Mahidol University ${ }^{4}$, \\ Institute of Science and Technology, Tokai University ${ }^{5}$ and \\ Department of Parasitology, Gunma University School of Medicine ${ }^{6}$
}

\begin{abstract}
Phospholipase A2 (PLA2) is the first enzyme in the arachidonate cascade, and is found in various mammals as well as insects and snake venom. In 1994, Vadas et al. found a rapid increase of levels of circulating PLA2 in children with $P$. falciparum, particularly so in patients with severe disease as manifested by high parasite burden, anemia, coma, and death. They also showed that the PLA2 level was closely related to the TNF level. In this study, we developed a new method of measuring serum PLA2 by ELISA, and investigated the serum PLA2 level in malaria patients using this method. We also investigated the dynamics of the serum PLA2 level through the course of malaria infection.

[Materials and Methods] Sera were collected from Thai $P$. falciparum and $P$. vivax infected symptomatic and parasitemic patients, who were hospitalized in the Hospital for Tropical Diseases, Mahidol University, Thailand. The fluorescence-ELISA for PLA2 measurement was developed using the sandwich method which used anti-human sperm PLA2 (human type II secretory PLA2) as the antigen, rabbit anti-porcine PLA2 anti-
\end{abstract}

body as the antibody for the first reaction, and alkaline phosphatase conjugated anti-rabbit antibody as the enzyme-labeled antibody for the second reaction. 4methyl-umbelliferyl phosphate was used as the enzyme substrate.

[Results and Conclusion] Of 73 falciparum malaria patients, 50 sera (68.5\%) showed a higher PLA2 level than that of healthy individuals. Amng patients with vivax malaria, 13 of 15 patients (80\%) showed a higher PLA2 level. The frequencies of this PLA2 in the group of patients as classified according to the WHO criteria for severity were $57.1 \%, 72,7 \%$, and $78.5 \%$ in falciparum malaria patients with mild, moderate, and severe, respectively. The PLA2 level also tended to be higher in patients with severe malaria group. Regarding the relation to the disease stage, the PLA2 level was high immediately after hospitalization, and rapidly decreased within one week. We consider that measurement of PLA2 in malaria patients during the early phase provides an important clue to predicting progression of the disease.

\section{POLYMORPHISM OF TNF- $\alpha$ PROMOTER REGION ASSOCIATED WITH SUSCEPTIBILITY TO CEREBRAL MALARIA IN THAILAND}

\author{
Kenji Hirayama ${ }^{1}$, Sornchai LoOAREesuwan ${ }^{2}$, Ratawan Ubalee ${ }^{1,2}$, \\ MiHOKO KIKUCHI ${ }^{1}$, O. TASANOR ${ }^{2}$, K. NABANGCHANG ${ }^{2}$, JUNTRA KARBWANG ${ }^{2}$, \\ M. TAKedA ${ }^{1}$, AKikata Kimura ${ }^{3}$, Kyogo Ito ${ }^{4}$ and Masamichi Aikawa ${ }^{5}$ \\ Department of Medical Zoology, Saitama Medical School ${ }^{1}$, \\ Faculty of Tropical Medicine, Mahidor University², \\ Medical Institute, Tokyo Medical and Dental University ${ }^{3}$, \\ Department of Immunology, Kurume University School of Medicine ${ }^{4}$ and \\ Research Institute of Medical Science, Tokai University ${ }^{5}$
}

To investigate the host genetic factors affecting the clinical course of falciparum malaria, polymorphism of $\mathrm{TNF}-\alpha$ promoter region was analyzed in the patients with different clinical severity of malaria. Two hundred and eight Thai patients with falciparum malaria at the Faculty of Tropical Medicine, Mahidol University in 
Bangkok and Two hundred and fifty-four Myanmar's patients with falciparum malaria at the Mae Sod Malaria clinic in Mae Sot located at the border between Thailand and Myanmar, were adopted. Among the Thai patients 76 were asymptomatic, 89 , severe and 43 , cerebral malaria, and among the Myanmar's patients (128 from Karen, 116 from other Burmese) 210 were asymptomatic and 44, cerebral malaria. Those patients were diagnosed by the WHO criteria. After the diagnosis, all the subjects were immediately treated. TNF- $\alpha 5^{\prime}-$ flanking region which is located within class III region of HLA, was revealed to be polymorphic in $-238,-308$,
$-857,-863,-1031$ positions from the initiation codon of $\mathrm{TNF}-\alpha$. In the patients there were at least 7 linkage groups identified and one of the groups $-857 \mathrm{C},-863 \mathrm{C}$, $-1031 \mathrm{~T}$ was significantly increased in the cerebral malaria. We also analyzed frequency of the promoter region polymorphism of TNF- $\alpha$ in Japanese and Thais and found that the susceptible type was dominant in Japanese $(\mathrm{Af}=82.3)$ compared with Thais $(\mathrm{Af}=7.5)$.

Our data suggested the TNF- $\alpha$ production at the infection is controled by the polymorphic promoter region of $\mathrm{TNF}-\alpha$ gene.

\title{
68 THE ROLE OF CR1 (COMPLEMENT RECEPTOR 1) ON ERYTHROCYTES IN THE DEVELOPMENT OF SEVERE MALARIA
}

\author{
Eiji Nagayasu ${ }^{1}$, Mamoru Ito ${ }^{2}$, Y. Nakano ${ }^{1}$, Minoru Kimura ${ }^{3}$, \\ SORNCHAI LOOAREESUWAN ${ }^{4}$ AND MASAMICHI AIKAWA ${ }^{1}$ \\ Research Institute of Science and Technology ${ }^{1}$, \\ Central Institute for Experimental Animals², \\ The Institute of Medical Science ${ }^{3}$, Tokai University and \\ Faculty of Tropical Medicine, Mahidol University ${ }^{4}$
}

\begin{abstract}
Complement receptor 1 on erythrocytes (E-CR1) shows an inherited numerical polymorphism (CR1 density polymorphism) which correlates with a RFLP of the CR1 gene. E-CR1 plays an essential role in the clearance of immune complexes from the circulation. On the other hand E-CR1 is also known as a receptor for erythrocyte rosetting (adhesion of $P$. falciparum infected erythrocytes to uninfected erythrocytes). To investigate the relationship between CR1 density polymorphism and disease severity, we typed 117 acute falciparum malaria patients for their genotypes of this polymorphism.
\end{abstract}

Patients diagnosed as having acute falciparum malaria were separated into severe or mild group according to the WHO criteria. Their genotypes were determined by PCR amplification of CR1 gene followed by restricton enzyme digestion (PCR-RFLP).

We have observed a significant higher frequency of homozygotes of CR1 low density allele in severe group as compared to mild group. Our results suggest that a genetically determined low CR1 density may be a risk factor for developing a more severe form of malaria because of their defective ability of the clearance of immune complexes.

\section{MEASUREMENT OF ANTI-MALARIAL ANTIBODIES FOR INHABITANTS IN MALARIA ENDEMIC AREAS USING RECOMBINANT PROTEINS OF PLASMODIUM FALCIPARUM AS ELISA ANTIGENS}

\author{
Hiroyuki Matsuoka, Kuni Iwai, Shigeto Yoshida, Meiji Arai, \\ ENJIE LUO AND AKIRA ISHII \\ Department of Medical Zoology, Jichi Medical School
}

We have produced recombinant malarial proteins using baculovirus-insect expression systems. So far we succeeded to express recombinant MSP-1 (rMSP-1:
Plasmodium falciparum merozoite surface protein, block 17) in silkworm hemolymph, and purified it using affinity chromatography with monoclonal antibody. Recom. 
binant SERA (rSERA: P. falciparum Serine Repeat Antigen) was produced in Trichoplusia ni cell expression system using no-protein culture medium. These recombinant proteins have been under evaluation for malaria vaccine candidates. $\mathrm{We}$, on the other hand, tested these proteins as ELISA antigens for measuring anti-malarial antibodies in malaria endemic areas.

Native malaria antigen was extracted from cultured $P$. falciparum as a control antigen (nPf). Two recombinant proteins (rMSP-1 and rSERA) and one native protein $(\mathrm{nPf})$ were diluted and filled in ELISA plates. Diluted sera from malaria endemic areas and non-endemic areas were reacted in the plates, and antihuman IgG conjugated with horse raddish peroxidase was added as the 2 nd antibody. Titres of anti-nPf and anti-rMSP-1 in individual sera were positively correlated. Titres of anti-nPf and anti-rSERA were correlated as well. These results indicate that recombinant proteins we produced can be used as ELISA antigens. High antibody titres to rMSP-1 and rSERA were obtained from persons whose age were 10 years or more. This suggests that antibodies to these antigens are induced after repeated malaria infection.

\title{
70 CULTIVATION OF PLASMODIUM FALCIPARUM ISOLATES UNDER THE ANAEROPACK $^{\text {TM }}$ GAS CONDITION IN A PORTABLE THERMOSTATIC INCUBATOR
}

\author{
Yasutaka Mizuno ${ }^{1,2,3}$, Toshimitsu Hatabu'2, Shin-ichiro KaWAZU ${ }^{2}$, \\ Hiroshi Ohtomo ${ }^{3}$, Mamoru Suzuki ${ }^{4}$ and Shigeyuki KanO ${ }^{2}$ \\ Department of Pediatrics ${ }^{1}$ and Department Tropical Medicine ${ }^{3}$, \\ Jikei University School of Medicine, \\ Research Institute International Medical Center of Japan ${ }^{2}$ and \\ Department of Parasitology, Gunma University School of Medicine ${ }^{4}$
}

Cultivation of Plasmodium falciparum (P.f.) in vitro requires lower oxygen concentration and appropriate $\mathrm{pH}$ condition. AnaeroPack ${ }^{\mathrm{TM}}$ Malaria culture kit (SUGIYAMA-GEN Co., Ltd.) was devised as a portable cultivation system which can maintain such proper conditions for P.f. parasites to grow in the specific sealed jar (AnaeroPack ${ }^{\mathrm{TM}}$ Kakugata jar, $2.5 l$ ). It was reported that the culture-adapted strains of P.f. could grow nicely in this system (Onda $e t$ al.). We examined if this system could also be used for the cultivation of newly isolated parasites from the patients. Infected erythrocytes taken from four patients (2 Japanese men, 1 Japanese woman and 1 Zambian man) were incubated under the following three different gas conditions; Mix gas $\left(5 \% \mathrm{CO}_{2}, 5 \% \mathrm{O}_{2}, 90 \% \mathrm{~N}_{2}\right)$, AnaeroPack ${ }^{\mathrm{TM}} \mathrm{CO}_{2}(15 \%$ $\left.\mathrm{O}_{2}, 6 \% \mathrm{CO}_{2}\right)$ and AnaeroPack ${ }^{\mathrm{TM}}$ plus $\left(5 \% \mathrm{O}_{2}, 5 \% \mathrm{CO}_{2}\right)$. The culture dishes were kept in the portable incubator,
Super duo cargo (SUGIYAMA-GEN Co., Ltd.), which can maintain a stable temperature inside at $37^{\circ} \mathrm{C}$ conditioned by a specific thermostat. The culture medium was changed every $24 \mathrm{hr}$ and an AnaeroPack ${ }^{\mathrm{TM}}$ gas generator was replaced by a new one.

We made slide smears from the culture suspension when the medium was changed, and counted the parasites under the microscopic observation. The parasite proliferation curves of all conditions were proved to be showing parallel curves each other. This finding showed that AnaeroPack ${ }^{\mathrm{TM}}$ Malaria culture system with the portable thermostatic incubator was an appropriate method not only for the cultivation of culture-adapted strains but also for that of newly isolated parasites. Important data on the epidemiology of drug resistant malaria will be collected by applying this new method to the field survey. 


\title{
71 EFFECT OF TETRACYCLINE AND MINOCYCLINE AGAINST PLASMODIUM FALCIPURUM IN VITRO
}

\author{
Quing Hua Lin ${ }^{1}$, Mino OhuE ${ }^{1}$, Tomoko Onda ${ }^{1}$, Ken Katakura ${ }^{1}$, \\ SHIGEYUKI KANO ${ }^{2}$ AND MAMORU SUZUKI ${ }^{1}$ \\ Department of Parasitology, Gunma University School of Medicine ${ }^{1}$ and \\ Research Institute of International Medical Center of Japan ${ }^{2}$
}

The emergence and spread of drug resistant Plasmodium falciparum is a major problem for chemotherapy of malaria. Development of potent antimalarials is important, but it is also necessary to investigate the possible use of existing antimicrobial agents, which have already been approved for the treatment of other infectious diseases. In this study, we examined effects of tetracycline (TC) and minocycline (MC) on the $P$. falciparum strains, which show different sensitivity to chloroquine $(\mathrm{CQ})$, mefloquine $(\mathrm{MQ})$ and pyrimethamine (PM) in vitro.

Parasites used in this study were the SGE-1 strain showing $\mathrm{CQ}$ sensitive (CQS), MQ sensitive (MQS) and $\mathrm{PM}$ sensitive (PMS), the $\mathrm{K} 1$ strain exhibiting $\mathrm{CQ}$ resistance (CQR), a clinical isolate exhibiting MQ resistance $(\mathrm{MQR})$, and other clinical isolate showing both $\mathrm{CQ}$ resistance $(\mathrm{CQR})$ and $\mathrm{PM}$ resistance $(\mathrm{PMR})$. In vitro drug susceptibility test was carried out by semi-microtechnique. Parasites were cultured for up to $96 \mathrm{hr}$ in the presence of different concentrations of drugs and 50\% inhibitory concentrations $\left(\mathrm{IC}_{50}\right)$ of the drugs were determined. The $\mathrm{IC}_{50}$ of $\mathrm{TC}$ and $\mathrm{MC}$ against the $\mathrm{SGE}-1$ strain at $96 \mathrm{hr}$ of culture were $1.07 \pm 0.74(\mathrm{n}=3)$ and $0.19 \pm 0.09$ $(\mathrm{n}=3) \mu \mathrm{g} / \mathrm{m} l$, respectively. A similar drug susceptibility was obtained with CQR, MQR and PMR parasites. Overall, highly lipophilic MC was about five times more effective than TC against $P$. falciparum proliferation.

In the presence of $\mathrm{TC}$ or MC, no matured schizonts but trophozoites with a nuclear shrinkage were observed at $72 \mathrm{hr}$ in Giemsa-stained smear preparations. Electron microscopy revealed that the endoplasmic reticulum and the mitochondria were dilated and that the cytoplasm contained numerous electron-dense vesicles with a single membrane. In addition, decreased accumulation of Rh123 dye was observed in the TC or MC-treated $P$. falciparum, suggesting damage of the mitochondria membrane of the parasites.

\section{DEVELOPMENT OF NEW ANTIMALARIAL DRUGS -THE ANTIMALARIAL ACTIVITY OF ENDOPEROXIDE ANALOGS-}

\author{
Yuki Ishizuka ${ }^{1}$, HYe-SOOK KIM ${ }^{1}$, Yusuke WATAYA ${ }^{1}$, Yoshiaki HAMAdA ${ }^{2}$, \\ KaOru Tsuchiya ${ }^{2}$, Araki Masuyama ${ }^{2}$ and Masatomo NoJima ${ }^{2}$ \\ Faculty of Pharmaceutical Sciences, Okayama University ${ }^{1}$ and \\ Faculty of Engineerings, Osaka University ${ }^{2}$
}

Based on the ancient Chinese herbal medicine, a new class of nonalkaloidal antimalarial compound quinghaosu was identified by organic chemists in the 1970s; characteristic of these potent and fast-acting antimalarial is their chemically unusual 1,2,4-trioxane pharmacophore unit. Clinically used examples of such trioxanes derived from Artemisia annua (quinghao) are natural artemisinin (quinghaosu) and it's derivatives which has stimulated extensive synthetic and mechanistic research into their novel mode of action. Thus, organic chemists have synthesized a large number of structurally diverse artemisinin analogs and several simplified 1,2,4-trioxanes have been also found to show remarkable activities against Plasmodium infections in vivo in animals. These discoveries prompted us to investigate new structures of antimalarial endoperoxides.

Now, we have confirmed the potential of $1,2,4,5-$ tetraoxacyclo- alkanes as a new class of simple peroxide antimalarial drugs. In the preliminary studies, some 1,2,4,5-tetraoxacycloalkanes have been found to be available for chloroquine resistant $P$. falciparum in vitro. For instance, 1,2,6,7-tetraoxaspiro [7.11] nonadecane $(\mathrm{N}-89)$ has a potent antimalarial activity for $P$. falciparum (K1 strain), the $\mathrm{EC}_{50}$ value of which is $2.6 \times 10^{-8} \mathrm{M}$. In contrast, the $50 \%$ inhibitory concentra- 
tion of against mouse mammary FM3A cells is $8.0 \times 10^{-6}$ $\mathrm{M}$, demonstrating tht the selective toxicity (307) is also remarkable. It should be noticed that these compounds are similar effective of artemisinin (the $\mathrm{EC}_{50}$ 's against $P$. falciparum and FM3A cells were $7.8 \times 10^{-9} \mathrm{M}$ and $1.0 \times 10^{-5} \mathrm{M}$, respectively). An in vitro test, morphological changes of malaria parasites during the treatment of N-89 against $P$. falciparum was studied. In these results, we have observed a condensation of para- site nuclei, shrunken cytosol in trophozoites and inhibition of schizont formation by micoscopy after treatment with 100 times the $\mathrm{EC}_{50}$ value of $\mathrm{N}-89\left(2.5 \times 10^{-6} \mathrm{M}\right)$ for $24 \mathrm{hr}$. The morphological changes in parasites induced by N-89 may be a consequence of several phenomena including inhibition of protein synthesis.

Our results may be helpful in the design of better chemotherapeutic endoperoxide in the worldwide fight against malaria.

\title{
73 DEVELOPMENT OF NEW ANTIMALARIAL DRUGS - IN VIVO ANTIMALARIAL ACTIVITY OF ENDOPEROXIDES-
}

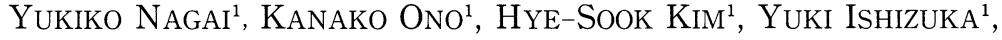 \\ Yusuke Wataya ${ }^{1}$, Yoshiaki Hamada ${ }^{2}$, KaORU TSUChiYa ${ }^{2}$, \\ ARAKI Masuyama ${ }^{2}$ and Masatomo NoJima ${ }^{2}$ \\ Faculty of Pharmaceutical Sciences, Okayama University ${ }^{1}$ and \\ Faculty of Engineerings, Osaka University ${ }^{2}$
}

1,2,4,5-Tetraoxacycloalkanes as analogs of artemisinin, were studied as antimalarial agents against Plasmodium falciparum in vitro and $P$. berghei in vivo. In our experiments, 1,2,6,7-tetraoxaspiro[7.11] nonadecane $(\mathrm{N}-89)$ has potent antimalarial activities and has been found to be available for chloroquine resistant $P$. falciparum (K1 strain), the $\mathrm{IC}_{50}$ value of which was $2.6 \times$ $10^{-8} \mathrm{M}$. The $\mathrm{IC}_{50}$ value of against mouse mammary FM3A cells was $8.0 \times 10^{-6} \mathrm{M}$, demonstrating that the selective toxicity (307) was also remarkable.

We investigated the in vivo antimalarial activities of $\mathrm{N}-89$ by 4 -day suppressive test. The $\mathrm{ED}_{50}$ value of the compound has shown that $12 \mathrm{mg} / \mathrm{kg} /$ day (ip), which was required to cause $50 \%$ suppression of $P$. berghei in mice. In the experiments, the dose of $50 \mathrm{mg} / \mathrm{kg} /$ day of $\mathrm{N}-89$ causes cure (for 4 mice in 5 tested mice), in which malaria parasites were not observed in circulating blood after 60 days. Furthermore, no side effects such as diarrhea, body weight loss and mortality were observed during treatment with $\mathrm{N}-89$ at doses by $1,600 \mathrm{mg} / \mathrm{kg}$ (ip).

As a control, mice treated with artemisinin $(50 \mathrm{mg} /$ $\mathrm{kg} /$ day, ip) were not cured and mice died due to $P$. berghei infection. These results may be helpful in the design of better chemotherapeutic 1,2,4,5-Tetraoxacycloalkanes in the worldwide fight against malaria.

\section{DEVELOPMENT OF NEW ANTIMALARIAL DRUGS -THE SEMI-SYNTHETIC ANTIMALARIAL ALKALOIDS FROM DICHROA FEBRIFUCA-}

\author{
HYE-SOOK KIM ${ }^{1}$, YUKI ISHIZUKA ${ }^{1}$, YUSUKe WATAYA ${ }^{1}$, \\ Yoshiaki TAKaya ${ }^{2}$, Hidehisa TASAKA ${ }^{2}$ AND Yoshiteru Oshima ${ }^{2}$ \\ Faculty of Pharmaceutical Sciences, Okayama University ${ }^{1}$ and \\ Faculty of Pharmaceutical Sciences, Tohoku University ${ }^{2}$
}

A number of medicines such as chloroquine and quinine are available for treatment of malaria, but the rapid development of drug resistance are a serious problem. Medicinal agents based on novel mechanisms of action are, therefore, required to overcome emergence of resistance and to control an ever-increasing number of epidemics caused by the malaria parasite. In China, the roots of $D$. febrifuga have been employed against malaria fevers. Febrifugine and isofebrifugine were isolated as potential antimalarial agents. The febrifugine was once submitted to clinical test, however, it is reported that the compounds have serious adverse 
reactions such as vomiting and diarrhea.

As part of a multidisciplinary research program on antimalarial natural products, we are screening plant extracts that are alleged to have antimalarial activity. As the results, we found the semi-synthetic compounds,
Df-1 and Df-2 (C-252), from febrifugine and isofebrifugine. Df-1 and Df-2 have potent antimalarial activities with higher therapeutical selectivity than febrifugine against $P$. falciparum in vitro and in vivo.

\title{
75 STUDIES OF ANTISENSE OLIGONUCLEOTIDE -EFFECTS AGAINST PLASMODIUM FALCIPURUM-
}

\author{
NAOMI IKemoto ${ }^{1}$, Hye-Sook KIM ${ }^{1}$, Makiko KAnAZAKI ${ }^{2}$, Yoshinito UenO ${ }^{2}$, \\ Satoshi Shuto ${ }^{2}$, Akira Matsuda ${ }^{2}$ and Yusuke Wataya ${ }^{1}$ \\ Faculty of Pharmaceutical Sciences, Okayama University ${ }^{1}$ and \\ Graduate School of Pharmaceutical Science, Hokkaido University ${ }^{2}$
}

Synthetic oligodeoxynucleotides (ODNs) have been shown to inhibit viral and cellular gene expression by sequence-specific antisense (AS) hybridization. AS ODNs inhibit specific protein synthesis and cell growth. Previously we designed and synthesized nuclease-resistant ODNs, phosphorothioate (PS) ODNs and ODNs containing $4^{\prime} \alpha-C$ - (2-aminoethyl) thymidines (4'-amino ODNs). In this study, we investigated inhibition of growth and mRNA levels of the malaria parasite, Plasmodium falciparum, in vitro culture using those AS ODNs in order to search for new target of antimalarial agent.

We examined antimalarial activity of AS ODNs (2030 mer) targeting mRNA encoded plasmodial enzymes such as dihydrofolate reductase (DHFR), dihydropteroate synthetase (DHPS) and succinate dehydrogenase (SDH) of $P$. falciparum (FCR-3 strain). AS ODN targeting mRNA of SDH iron-sulfur subunit (IP AS ODN) showed most effective inhibition of growth of $P$. falciparum in vitro. Our results suggested that IP should be essential for parasite growth, and therefore it would be a good target for anti-malarial agents. Furthermore we found that 4'-amino AS ODNs have less non-specific cytotoxicity compared with PS AS ODNs. We performed quantitative RT-PCR assay to determine the IP mRNA level in the parasites after the $24 \mathrm{hr}$ treatment with IP PS AS. As the results, IP mRNA level was strikingly decreased by treatment with IP AS ODN. We guessed that the antimalarial activity of IP AS ODN was resulted in specific decrease of the complementary mRNA level. From the results, we concluded that IP was essential for parasite growth.

These results suggest that $\mathrm{SDH}$ is one of the candidates of the target for novel antimalarial drugs. For search and assessment of new drug targets rather than for therapeutic drugs, the combination of AS ODNs and quantitative RT-PCR methods is effective in the case of disease having economical problems such as malaria.

\section{RNA EXPRESSION PATTERN OF CATALYTIC SUBUNIT OF MITOCHONDRIAL COMPLEX II FROM PLASMODIUM FALCIPARUM}

\author{
SATORU TAKeo AND Kiyoshi Kita \\ Department of Biomedical Science, Graduate School of Medicine, \\ The University of Tokyo
}

Chemotherapy of malaria using chloroquine and alternative compounds has been followed by the appearance of resistant parasites as shown in many epidemiological studies. The major reason for this vicious cycle is that the modes of action of many antimalarials are poorly understood. This lack of knowledge would be efficiently overcome by exploring the biology of Plasmodium in the asexual erythrocytic stage and focusing on preferential targets.

The morphological difference and the favorable effect of low $\mathrm{O}_{2}$ level on the in vitro cultivation of Plasmodium falciparum suggests that the physiological 
role of malarial mitochondria, including that in energy metabolism, is different from human host. The studies so far did not support the existence of complete TCA "cycle" in Plasmodium, but suggested the functional parasite electron transport system. For elucidating the role of this organelle, we have focused on complex II (succinate dehydrogenase, SDH) because it is exclusively mitochondrial enzyme and plays a unique role as a direct link between these two major mitochondrial systems. And furthermore, this enzyme functions as fumarate reductase (FRD), opposite to $\mathrm{SDH}$, under anaerobic condition in some parasites such as adult Ascaris suum. Complex II is generally composed of four subunits, and we have already cloned the genes for two catalytic subunits (flavoprotein subunit: Fp and iron-sulfur subunit: Ip) from P. falciparum. Northern analysis and RT-PCR also demonstrated the expression of two genes at intraerythrocytic stage parasite.

In the present study, the expression pattern of the transcripts of the gene for Fp was analyzed using gametocyte-producing clone of $P$. falciparum (3D7) cultivated in vitro. The pattern of RNA level is most abundant in gametocyte, the sexual stage responsible for malaria transmission to the mosquito vector. In asexual stages $(3,21,32,43,50 \mathrm{hrs}$ after synchronization by sorbitol), transcript level is relatively high at ring form and down-regulated at trophozoite and schizont stages. This result is consistent with that from mitochondrial adenylate translocase (ADP/ATP transporter). The expression pattern of plasmodial $6 \mathrm{~Kb}$ element-encoding cytochrome $c$ oxidase (electron transport chain enzyme complex IV) subunit I (COI) and cytochrome $b$ of ubiquinone-cytochrome $c$ oxidoreductase (complex III) (CYb) is also similar to Fp in asexual stages, but they are down-regulated in gametocyte. However, this result of two proteins encoded on the putative malarial mitochondrial DNA is quite different from that reported by Feagin et al. (Exp. Parasitol., 80, 430-440, 1995). The result encourages us to confirm the expression pattern using FCR3 strain which rarely produces gametocytes, and analysis is now in progress. It is also interesting from the viewpoint of the co-expression of mitochondrial proteins encoded on different genetic elements because complex II catalytic subunits and ADP/ATP transporter are encoded not on mitochondrial DNA, but on parasite nucleus.

\title{
77 PRIMARY STRUCTURE OF THE RHOPTRY PROTEIN, RYRHOP100, OF PLASMODIUM YOELII MEROZOITE
}

\author{
Michinori Shirano, TAKafumi Tsuboi, Mayumi Tachibana and \\ Motomi TORII \\ Department of Molecular Parasitology, \\ Ehime University School of Medicine
}

All invasive forms of Apicomplexa possess a complex of apical organelles, which comprise rhoptries, dense granules and micronemes. The rhoptries are pearshaped, electron-dense, membrane-bound organelles and are considered to have roles in host cell attachment, invasion and formation of parasitophorous vacuole membrane. We have developed monoclonal antibodies $(\mathrm{mAb})$ against rhoptry proteins of Plasmodium yoelii merozoites. mAb\# 25 reacted against $140 / 125 \mathrm{kDa}$ antigens and $\mathrm{mAb} \# 32$ reacted against $100 \mathrm{kDa}$ antigen, respectively. Subcellular localization of the antigens was confirmed by IFA and immunoelectron microscopy.

These antigens appeared on the rhoptries of the $P$. yoelii merozoites. We affinity purified $140 \mathrm{kDa}$ and 100 $\mathrm{kDa} P$. yoelii rhoptry proteins by using the affinity column conjugated with $\mathrm{mAb} \# 25$. After partial purification, we analyzed the partial amino acid sequences of the $P$. yoelii RhopH proteins. We synthesized several sets of degenerate oligonucleotides based on the amino acid sequences of peptides obtained from the $100 \mathrm{kDa}-$ rhoptry protein of $P$. yoelii. By using these primers, we partially cloned the gene which encode PyRhop100 from the genomic DNA and cDNA of $P$. yoelii merozoites. Then, we synthesized three synthetic peptides based on the deduced amino acid sequences of PyRhop100. By using the mouse immune-sera against these synthetic peptides, we detected the positive IFA-staining of $P$. yoelii merozoite rhoptries. We also detected that the homologue of PyRhop100 protein was a $105 \mathrm{kDa}$ RhopH3 of $P$. falciparum by the database search in about $40 \%$ amino acid sequence identities.

In comparison with these amino acid sequences of PyRhop100 and RfRhopH3, almost all the cysteine residues were conserved between PyRhop100 and 
PfRhopH3. These results suggest that the tertiary structure of the PyRhop100 and PfRhopH3 proteins have a biological importance on the merozoite invasion into the erythrocytes.

\title{
78 DETECTION OF THE SEQUENCE POLYMORPHISM IN PLASMODIUM VIVAX TRANSMISSION-BLOKING VACCINE CANDIDATE ANTIGENS BY USING PCR-SSCP
}

\author{
Takafumi Tsuboi, Miyuki Yano, Mayumi Tachibana and Motomi Tori \\ Department of Molecular Parasitology, \\ Ehime University School of Medicine
}

In many malarious regions outside of Africa, development of transmission-blocking vaccine will require activity against both Plasmodium falciparum and $P$. vivax if the vaccine is to have a large impact on the overall morbidity due to malaria in that region. We have recently cloned the genes, Pvs25 and Pvs28, encoding two major surface proteins on $P$. vivax zygote/ookinetes, which are malaria transmission-blocking vaccine candidates. Polymorphism of malaria parasite antigens makes the determination of their amino acid sequence diversity in field isolates prior to vaccine trials a prudent exercise. The ookinete surface proteins of $P$. falciparum, Pfs25 and Pfs28, which are thought to be expressed predominantly while the parasite resides in the mosquito, are usually highly conserved for malaria surface antigens. Only two conserved amino acid substitutions were found in Pfs25 and one conserved substitution in Pfs28 to date.

In order to characterize the sequence polymorphism of Pvs25 and Pvs28, we PCR-amplified and determined the DNA sequence of these two genes in genomic DNA of $P$. vivax extracted from a laboratory strain, Sall, an Indian isolate and several Bangladesh isolates. In Pvs25, we found only three point mutations that would result in amino acid substitutions. We also succeeded to distinguish the four gene types results from the above point mutations of Pvs25 by using PCR-SSCP.

In contrast, the Pvs28 gene had more point mutations. The most striking variation we detected in Pvs28 was the four to seven tandem repeats of GSGGE/D. We also tried to distinguish the sixteen gene types results from the above point mutations of Pvs28 by using PCRSSCP, however, we could not distinguish these gene types by using PCR-fragments in full length (694 bp). Finally, we succeeded to distinguish the twelve Pvs28 gene types out of sixteen by using PCR-fragments digested with BsmI (125/336/233 bp).

\section{INHIBITORY EFFECT OF DINITROANILINE HERBICIDES ON THE GROWTH OF ENTAMOEBA HISTL YTICA}

\author{
Asao Makioka ${ }^{1}$, Masahiro Kumagai ${ }^{1}$, Hiroshi Ohtomo ${ }^{1}$, \\ SEIKI Kobayashi ${ }^{2}$ AND TSutomu TAKEUCHI ${ }^{2}$ \\ Department of Tropical Medicine, Jikei University School of Medicine ${ }^{1}$ and \\ Department of Tropical Medicine \& Parasitology, \\ Keio University School of Medicine ${ }^{2}$
}

Effect of dinitroaniline herbicides oryzalin and trifluralin on the growth of Entamoeba histolytica was examined. Oryzalin inhibited the growth of $E$. histolytica strain HM-1:IMSS. Trifluralin was less effective than oryzalin for this parasite. E. histolytica was more resistant to these dinitroanilines than other parasitic protozoa examined so far, including Leishmania species, Trypanosoma brucei, Plasmodium falciparum,
Toxoplasma gondii and Cryptosporidium parvum. Colchicine, a potent microtubule inhibitor of animal cells, was much less effective for $E$. histolytica even at very high concentrations.

A reptilian parasite $E$. invadens strain IP-1, examined for comparison, was more resistant to these dinitroanilines than $E$. histolytica. Accumulation of $E$. histolytica trophozoites at mitotic stage was observed 
during culture with $100 \mu \mathrm{M}$ of oryzalin. The inhibitory effect of oryzalin on the growth of $E$. histolytica was abrogated by removal of the drug that was exposed to trophozoites at a concentration of $100 \mu \mathrm{M}$ for 2 days.

In parallel to the recovery of growth after removal of the drug, percentage of trophozoites at mitotic stage reduced to normal level. Thus the results indicate that treatment of trophozoites with oryzalin arrests their mitosis and its effect is reversible. Therefore, oryzalin is a useful molecular tool for studies relating to cell cycle of this parasite.

\title{
80 A STAGE-SPECIFIC IMMUNODOMINANT GLYCOPROTEIN APPEARED IN ENCYSTING ENTAMOEBA INVADENS
}

\author{
Asao Makioka ${ }^{1}$, Masahiro Kumagai ${ }^{1}$, Hiroshi Ohtomo ${ }^{1}$, \\ SEIKI Kobayashi ${ }^{2}$ And Tsutomu TAKEUCHI ${ }^{2}$ \\ Department of Tropical Medicine, Jikei University School of Medicine ${ }^{1}$ and \\ Department of Tropical Medicine \& Parasitology, \\ Keio University School of Medicine ${ }^{2}$
}

Appearance of cyst-specific proteins in encysting Entamoeba invadens and their immunogenicity were examined by sodium dodecyl sulfate-polyacrylamide gel electrophoresis and immunoblotting using an axenic encystation system in vitro. A rabbit antiserum against trophozoites of $E$. invadens reacted with a number of proteins of cysts after 1-4 days of encystation. Thus, a number of cyst proteins remained antigenically unchanged as common antigens of the two forms after transformation from trophozoites to cysts.

A rabbit antiserum against cysts also reacted with the trophozoite proteins as well as the cyst ones. The most interesting results were that the rabbit anti-cyst serum reacted predominantly with an $88 \mathrm{kDa}$ protein of cysts after 1 day of encystation. The $88 \mathrm{kDa}$ protein reacted with the anti-cyst serum absorbed with troph- ozoite proteins so that it was cyst-specific. Reactivity of the $88 \mathrm{kDa}$ protein of cysts with the absorbed anticyst serum decreased as encystation proceeded.

When soluble and particulate fractions prepared from cysts after 1 day of encystation were examined by electrophoresis and immunoblotting, the $88 \mathrm{kDa}$ protein that reacted with the absorbed anti-cyst serum was found to be present in the particulate fraction which was rich in the cell wall fragments and stained with the periodic acid-Schiff's reagent, indicating that it is a glycoprotein. The results indicate that encystation is accompanied by appearance of the cyst-specific $88 \mathrm{kDa}$ glycoprotein which is immunodominant and most abundantly expressed in cysts after 1 day of encystation and appears to be associated with the cyst wall.

\section{QUANTITATIVE CHANGE OF THIOL COMPOUNDS WITH THE GROWTH OF ENTAMOEBA HISTLYTICA, IN THE SUPERNATANT OF EXOGENOUS CYSTEINE FREE AXENIC CULTURE MEDIUM}

\author{
Nobuko Nangi, Masanori Kobayashi and Tsutomu Takeuchi \\ Department of Tropical Medicine \& Parasitology, \\ Keio University School of Medicine
}

Cysteine is known as an essential and specific compound for the growth of Entamoeba histolytica (E.h) in TYI-S-33 axenic culture system (Gillin and Diamond, 1981, 1984). And in this culture system, E.h cannot grow without one of either exogenous cysteine (or cystine) or ascorbic acid. We designed and established a newly system [C\&A (-) system] removed exogenous cysteine (or cystine) and ascorbic acid from filter sterilized modified YI-S medium (Diamond, 1995), for analysis of cysteine synthesized by E.h itself. Exogenous ascorbic acid is known as the only compound to make successful culture of axenic E.h possible in exogenous cysteine (or 
cystine) free TYI-S-33 medium (Gillin and Diamond, 1981).

[Characteristics of amebae in C\&A (-) system] 1) The doubling time of trophozoite of E.h (HM-1:IMSS cl 6) growing in C\&A (-) system did need about two times as long as that in filter sterilized YI-S medium. 2) Intracellular vacuoles of HM-1:IMSS cl 6 (Clone 6) diminished the size electron microscopically as compared with same strain of amebae in TYI-S and filter sterilized YI-S medium.

[Results of SH quantitative assay in C\&A (-) system] 1) Amount of $\mathrm{SH}$ compounds in the supernatant of ameba (Clone 6) growing medium increased with the growth of Clone 6. 2) Released cysteine proteinase from Clone 6 seemed form a part of this $\mathrm{SH}$ compounds. Because activity of cysteine proteinase in the supernatant also increased with the growth of Clone 6 .

[Discussion] E.h can grow without exogenous cysteine (or cystine) or ascorbic acid. However, the E.h grown in C\&A (-) system were broken easily when transferred into isotonic buffer system as compared with E.h grown in cysteine containing medium. It seems that E.h requires plenty of cysteine for the stable growth, and exogenous cysteine is most available supplement.

\title{
82 CONGENITAL CHAGAS' DISEASE AND ITS ENVIRONMENTAL FACTORS IN SANTA CRUZ, BOLIVIA
}

\author{
SACHIO MiURA ${ }^{1}$, KeIICHI FuKUdA ${ }^{2}$, KensuKe SEKI ${ }^{3}$, \\ Masahiro Horio ${ }^{4}$ AND TSUtomu TAKeUCHI ${ }^{1}$ \\ Department of Tropical Medicine \& Parasitology ${ }^{1}$ and \\ Department of Internal Medicine ${ }^{2}$, Keio University School of Medicine \\ Department of Environmental Health, \\ School of Health Sciences, Kyorin University ${ }^{3}$ and \\ Department of Parasitology and Tropical Public Health, \\ University of Occupational and Environmental Health ${ }^{4}$
}

The reported birth number of congenital infection of Chagas' disease in Bolivia shows marked difference compared with its neighbor countries. We researched the inhabited environment of patient's and the living condition of triatomine bugs to prevent Chagas' disease.

In the prefectural maternity hospital in Santa Cruz, Bolivia, the antibody against $T$. cruzi of pregnant women were examined by IHA and congenital Chagas' disease of newborn were diagnosed by Strout method using umbilical cord blood. We researched about the following, inhabited environment of the newborn which were diagnosed as congenital Chagas' disease; the living condition of Triatoma around the house, the structure of the house, the inhabited condition of other blood-sucking insects and the possibility of contact with reservoir host. We also studied about awareness for Chagas' disease and serodiagnosis by IHA to inhabitant and researched about the prevalence of Chagas' disease in this area.

The newborn babies of congenital infection were 31 cases out of 1,936, and more than 20 cases were detected T. cruzi-DNA by PCR. Half of the congenitally infected babies live in the environment where the vector inhabits in without any treatment, and need immediately prevent measure against Chagas' disease. 


\title{
83 TRIAL TO DETECT OF TRYPANOSOMA CRUZI DNA FROM DRIED FECES OF TRIATOMINE BUGS
}

\author{
Shinjiro Hamano ${ }^{1}$, Masahiro Horio ${ }^{2}$, Sachio Miura ${ }^{3}$, Hiroo Higo $^{1}$, \\ Kanami NodA ${ }^{1}$, IsAo TADA ${ }^{1}$ And Tsutomu TAKEUCHI ${ }^{3}$ \\ Department of Microbiology (Parasitology), \\ Graduate School of Medical Sciences, Kyushu University ${ }^{1}$, \\ Department of Parasitology, Faculty of Medicine, \\ University of Occupational and Environmental Health ${ }^{2}$ and \\ Department of Tropical Medicine \& Parasitology, \\ Keio University School of Medicine ${ }^{3}$
}

From a viewpoint of public health, it is important to examine the distribution of triatomine and the infection rate of triatomines living in the houses. However, collecting live triatomes in the field involves a great deal of trouble and risk. In this study, we tried to detect $T$. cruzi DNA in Triatomine dried feces collected from the wall of a brick-built house in Bolivia, where is endemic area for Chagas' disease.

The primers (P35/P36) were chosen to amplify the conserved resion within the minirepeats of $T$. cruzi kinetoplast DNA minicircles. The primers were confirmed to amplify $330 \mathrm{bp}$ long product from different strains of $T$. cruzi with typical zymodem patterns, including isolates both from human and triatomine and from Central and South America. Triatoma infestans naturally infected with $T$. cruzi in Bolivia allowed to excrete feces on filter paper. The filter papers with fresh feces were preserved in the incubator at $25^{\circ} \mathrm{C}$ for 2 weeks to 6 months or at $40^{\circ} \mathrm{C}$ for 4 weeks. T. cruzi DNA was detected in the dried feces by PCR even after the exposure to an artificial environment for 6 months. Furthermore, DNA of $T$. cruzi was actually detected in the dried feces collected from the wall of a brick-built house in Bolivia. The results indicate that PCR can be a good tool for surveillance of the infection rate of triatomines which live in crevices in the walls, roofs and holes of poor houses.

\section{VARIATION OF PROTEINS AMONG DIFFERENT ISOLATES OF TR YPANOSOMA CRUZI}

\author{
Jiang-Bing Mu' ${ }^{1}$, Toshio Sone ${ }^{1}$, Tetsuo Yanagi², Cariota Montroy ${ }^{3}$, \\ Minoko KIKUChI ${ }^{1}$, Isao TAdA ${ }^{4}$ AND Kenji HiRAyama ${ }^{1}$ \\ Department of Medical Zoology, Saitama Medical School ${ }^{1}$, \\ Department of Protozoology, Institute of Tropical Medicine, \\ Nagasaki University ${ }^{2}$, \\ Department of Cytohistology, Faculty of Chemical Science and Pharmacy, \\ San Carlos University, Guatemala ${ }^{3}$ and \\ Department of Parasitology, Faculty of Medicine, Kyushu University ${ }^{4}$
}

Trypanosoma cruzi is a causative parasitic protozoon for Chagas' disease in South and Central America. Previous studies on isozyme pattern and DNA polymorphism analyses have been carried out about various isolates of $T$. cruzi, and the genetic variations among individual zymodemes have been reported. To estimate the variability within the species of $T$. cruzi, two-dimensional gel electrophoresis (2D-PAGE) of the proteins extracted from 21 isolates of epimastigote stage of $T$. cruzi was performed.
Epimastigote form of $T$. cruzi, isolated in Guatemala, Colombia, Brazil, Peru and Chile, was grown in Liver infusion tryptose (LIT) medium. Those were harvested and were lysed by PBS containing $2 \%$ Triton X-100. Soluble proteins obtained were examined to separate in the gel by 2D-PAGE according to the method of O'Farrell. The polypeptide spots were detected on the gel after staining with coomassie brilliant blue $\mathrm{R}-250$.

Move than 400 polypeptide spots were detected in 
each of 21-gel profile. We compared the presence or absence of the spots between the two isolates in all combinations to calculate percent difference. The values obtained were divided into two groups, one showed over $6 \%$ and another was less than $3 \%$. Twenty-one isolates were clearly classified into three groups, in case that the isolates showing $3 \%$ spot difference were clustered into the same group. T. cruzi among the other groups may be genetically more variable than those in a same group.

\title{
85 IMMUNOGENETIC ANALYSIS OF CHAGAS' DISEASE
}

\author{
Kayano Aida ${ }^{1}$, Sandra Juares ${ }^{1}$, Minoko KikUchi ${ }^{1}$, Kenji Hirayama ${ }^{1}$, \\ Tetsuo Yanagi ${ }^{2}$, Maria Paula Leon ${ }^{3}$, Satoshi Kaneko ${ }^{4}$, Oscar Ayau ${ }^{4}$, Toshio Sone ${ }^{1}$, \\ AKIKATA KimURA ${ }^{5}$, KYogo Ito ${ }^{6}$ AND Isao TADA ${ }^{7}$ \\ Department of Medical Zoology, Saitama Medical School ${ }^{1}$, \\ Department of Protozoology, Institute of Tropical Medicine, \\ Nagasaki University ${ }^{2}$, \\ Department of Histocytology, School of Pharmacy, \\ San Carlos University, Guatemala ${ }^{3}$ JICA Guatemara ${ }^{4}$, \\ Department of Molecular Pathogenesis, Division of Adult Disease, \\ Medical Research Institute, Tokyo Medical and Dental University ${ }^{5}$, \\ Department of Immunology, Faculty of Medicine, Kurume University ${ }^{6}$ and \\ Department of Parasitology, Faculty of Medicine, Kyushu University ${ }^{7}$
}

Chagas' disease is caused by a protozoan parasite Trypanosoma cruzi. Whether the infected individuals are able to eliminate the organism or develop chronic Chagas' disease with cardiopathy is unpredictable. In the present study, to reveal the host genetic factors that influence susceptibility to Chagas' disease, we typed 44 unrelated, seropositive Chagas' patients at the Department of Cardiology, Zacapa National Hospital, Guatemala, and 138 seronegative controls for polymorphisms of HLA-DQB1 and DPB1.

Thirty-one alleles of HLA-DPB1 were detected in the subjects. The frequency of HLA-DPB1*5101 was increased in the patients $\left(\chi^{2}=7.31, \mathrm{P}=0.0068, \mathrm{Pc}=0.19\right.$, $\mathrm{OR}=3.43,95 \% \mathrm{Cl} 1.36-8.68)$. Twenty alleles of HLADQB1 were detected, however, there was no association between HLA-DQB1 alleles and seropositivity. We have reported that HLA-B35 and MICA-A5 increased the risk for Chagas' disease, and that the effects of the two alleles on susceptibility were synergistic.

In the present study, there was positive linkage disequilibrium between HLA-DPB1*5101 and HLAB35. In conclusion, we suggest that HLA class I influences the susceptibility for Chagas' disease more than HLA class II.

\section{ANTIPROTOZOAN ACTIVITY OF MARINE SPONGE EXTRACTS}

\author{
Takeshi Mizushima ${ }^{1}$, Yuko Katakai ${ }^{1}$, Sukumawati Basuki ${ }^{1}$, Yasuyuki Goto ${ }^{1}$, \\ Yoichi NAKAO ${ }^{2}$, Shigeki Matsunaga ${ }^{2}$, Nobuhiro Fusetani ${ }^{2}$, \\ TAKASHI ONODERA ${ }^{1}$ AND Yoshitsugu MATSUMOTO ${ }^{1}$ \\ Department of Molecular Immunology ${ }^{1}$ and Department of Marine Biochemistry ${ }^{2}$, \\ School of Agricultural and Life Sciences, The University of Tokyo
}

Discovery of new therapeutic agents against protozoan diseases is in urgent need. Marine sponges have received much attention as potential sources of such new agents. In this study, antiprotozoan activity of marine sponge extracts were examined using in vitro culture of erythrocytic stages of Plasmodium falciparum FCR-3 and promastigotes of Leishmania donovani (MHOM/IN/80/DD8) and L. amazonensis (MPRO/ BR/72/M1845). Ninety three sponge specimens were obtained from the East China Sea. Hydrophilic and 
hydrophobic fractions were prepared by partition between chloroform and water of ethanol extract from each specimen. To analyze in vitro inhibitory effects of samples on proliferation of Leishmania parasites, Tetracolor One proliferation assay kit (Seikagaku Corporation, Japan) was used. For evaluation of malarial parasite growth, direct counting of infected erythrocytes were performed using Giemsa stained smears. Two hydrophobic samples (E23 and E65) showed 100\% growth inhibitory effect to $P$. falciparum at the concentration of $1 \mu \mathrm{g} / \mathrm{m} l$. On the other hand, the $50 \%$ growth inhibitory concentrations $\left(\mathrm{IC}_{50} \mathrm{~s}\right)$ of E34, E45 and E65 to $L$. donovani were $0.8,0.3$ and $0.3 \mu \mathrm{g} / \mathrm{m} l$, respectively. E34 and E65 were from Theonella sp. and Mycale sp., respectively, and the sponge from which E45 was extracted is unidentified. Cytotoxity to p388 murine leukemia cells (JCRB17) was also examined. $\mathrm{IC}_{50} \mathrm{~s}$ of E23, E34, E45, and E65 to p388 were $5 \mu \mathrm{g} / \mathrm{m} l, 2.2 \mu \mathrm{g} / \mathrm{m} l$, $2.2 \mu \mathrm{g} / \mathrm{m} l$, and $0.004 \mu \mathrm{g} / \mathrm{m} l$, respectively. These samples were further separated on ODS short columns with stepwise gradient solvent systems $\{50 \%, 75 \%, 100 \%$ methanol and chloroform-methanol-water (7:3:0.5) $\}$. $75 \%$ methanol eluted fractions were the most effective in each sample $\left(\mathrm{IC}_{50}\right.$ of E65 to $P$. faliciparum $=2 \mathrm{ng} / \mathrm{m} l$, $\mathrm{IC}_{50} \mathrm{~S}$ of E34, E45, and $\mathrm{E} 65$ to $L$. donovani $=100 \mathrm{ng} / \mathrm{m} l, 30$ $\mathrm{ng} / \mathrm{m} l$, and $8 \mathrm{ng} / \mathrm{m} l$, respectively). These results suggest marine sponge contain antiprotozoan chemicals and might be a potent source of new antiprotozoan agents.

\title{
87 NUCLEOTIDE SEQUENCE VARIATIONS OF THE CYTOCHROME C OXIDASE SUBUNIT I GENE WITHIN PHLEBOTOMUS SPECIES, VECTOR INSECTS FOR LEISHMANIASIS
}

\author{
Chizu Sanjoba ${ }^{1}$, Mikiko Yamauchi ${ }^{1}$, Yusuf OzBel ${ }^{2}$, Tetsuhiko Sasaki ${ }^{3}$, \\ Yasunobu Matsumoto ${ }^{1}$, TAKashi Onodera ${ }^{1}$ And Yoshitsugu Matsumoto ${ }^{1}$ \\ Department of Molecular Immunology, \\ School of Agricultural and Life Sciences ${ }^{1}$, \\ Department of Biological Sciences ${ }^{3}$, The University of Tokyo and \\ Department of Parasitology, Ege University ${ }^{2}$
}

Leishmaniasis is transmitted by vector insects belonging to the genus Phlebotomus in Old World and the genus Lutzomyia in New World. Morphological identification of species within the genus Phlebotomus is complex and causes controversy sometimes. In an attempt to characterize objectively the various species, the nucleotide sequence of a region of the mitochondrial cytochrome $\mathrm{C}$ oxidase subunit I (COI) gene was determined for four species of Phlebotomus, i.e., Phlebotomus papatasi, $P$. sergenti, $P$. major and $P$. simici. Total DNA was extracted separately from three individuals from each species which were collected in Turkey and identified morphologically by Dr. Yusuf Ozbel. PCR was carried out using $2.5 \mu l$ of extract DNA as the template, 25 pmol of the primers, $100 \mu \mathrm{M}$ dNTPs, $1 \mathrm{mM}$ $\mathrm{MgCl}_{2}, 2.5 \mathrm{U}$ Taq DNA polymerase in the buffer recommended by the manufacturer.

The primers were designed based on the COI sequence published for Drosophila yakuba. After amplification, the amplified products were purified and cloned into the vector pT7 Blue. Sequencing of the clones was performed by the dideoxy chain-termination method. The sequence of $D$. yakuba was also examined for comparative analysis. The COI gene sequence obtained was the same in length (314 bp) among all specimens. The nucleotide sequence analysis of the COI gene showed that $P$. simici, $P$. papatasi and $P$. sergenti are $84.3 \%(265 / 314 \mathrm{bp}), 85.3 \%(268 / 314 \mathrm{bp})$ and $83.4 \%(262 /$ $314 \mathrm{bp}$ ) identical to $P$. major, respectively. P. papatasi and $P$. sergenti are $84.0 \%(264 / 314 \mathrm{bp})$ and $83.1 \%(261 /$ $314 \mathrm{bp}$ ) identical to $P$. simici, respectively. $P$. papatasi and $P$. sergenti have the lowest homology at $80.8 \%$ (254/ $314 \mathrm{bp})$. The four species of Phlebotomus were clearly distinguished based on the nucleotide sequences. The identification of Phlebotomus species using COI gene nucleotide sequences were correspondent with the morphological identification. We thus conclude that nucleotide sequences of the COI gene can be used for reliable identification of Phlebotomus species. 


\title{
88 PCR-BASED DIFFERENTIATION OF THE SPECIES COMPLEXES IN LEISHMANIA SPP.
}

\author{
ShIN-ICHIRO KAWAZU ${ }^{1}$, Ken KatAKURA ${ }^{2}$, KoICHI NAGAKURA ${ }^{3}$, \\ Toshimitsu Hatabu ${ }^{4}$, Mamoru Ito ${ }^{5}$, Yutaka NaKaI ${ }^{6}$, Masamichi Aikawa $^{7}$, \\ K.-P. Chang $^{8}$, Tsugihiko Kamio ${ }^{9}$, Shigeyuki Kano ${ }^{1}$ and Yoshitsugu Matsumoto 4 \\ Research Institute of International Medical Center of Japan ${ }^{1}$, \\ Department of Parasitology, Gunma University School of Medicine ${ }^{2}$ \\ Tokai University School of Medicine ${ }^{3}$, \\ School of Agriculture and Life Science, The University of Tokyo ${ }^{4}$, \\ Central Institute of Experimental Animals ${ }^{5}$, \\ Department of Animal Microbiology and Parasitology, Tohoku University ${ }^{6}$, \\ Research Institute of Medical Science and Technology, \\ Tokai University ${ }^{7}$ and \\ Finch University of Health Sciences/The Chicago Medical School ${ }^{8}$ and \\ National Institute of Animal Health ${ }^{9}$
}

Leishmaniases are vector-borne and largely zoonotic diseases caused by parasitic protozoa in the genus Leishmania. The genus comprises some 30 species of mammalian parasites, of which 21 are known to infect humans. As a matter of clinical convenience, they are often classified into four assemblages (species-complex) according to both the geographic origin (Old World and New World) and the clinical types of the disease they produce (inapparent infections to various forms of cutaneous and visceral diseases). The classification of the parasites based on the species-complex often provide useful information for understanding the epidemiology of the disease, for example when characterize the parasite stocks isolated from sandfly vectors or the reservoir animals.
The gene encoding $\xi$-crystallin/NADPH oxidoreductase homologue (p36) is single-copied per haploid genome highly conserved in the Leishmania spp. The p36 gene has been reported to be useful marker to classify the parasite stocks into the four species-complexes. In the present study, we PCR-amplified $976 \mathrm{bp}$ of this $\sim 1 \mathrm{~kb}$ gene from 7 isolates, representing $L$. tropica complex or L. donovani complex. Following amplification, the genes were clearly differentiated using the restriction enzymes sites that were not shared between them. The result indicated that the p36 gene was suitable for differentiation of the 2 species-complexes that coexisted in the disease-endemic foci in Eurasian and African continents.

\section{ULTRASTRUCTURAL AND PATHOLOGICAL STUDY OF THE LESION OF DIFFUGE CUTANEOUS LEISHMANIASIS (DCL) PATIENT}

\author{
Motoyoshi Maruno ${ }^{1}$, Noor Mohammed Kaskhel $Y^{1}$, Atsushi Takamiyagi ${ }^{1}$, \\ Hiroshi Uezato ${ }^{1}$, Shigeo Nonaka ${ }^{1}$, \\ Gomez E.A. LANDRIES ${ }^{2}$ AND YoshiHISA HASHIGUCHI ${ }^{3}$ \\ Department of Dermatology, Faculty of Medicine, \\ University of the Ryukyus ${ }^{1}$, Deparatmento de Medicina Tropical, \\ Universidad Catolica Santiago de Guayaquil, Ecuador ${ }^{2}$ and \\ Department of Parasitology, Kochi Medical School ${ }^{3}$
}

We examined the ultrastructural and pathological difference of skin lesion between improving and worse period of a male DCL patient in Ecuador, South America. Together, we compared with LCL (localized cutaneous leishmaniasis) skin lesion. Skin samples were taken from the same lesion in both period and cut into two pieces for light and electron microscopic examination.

Immunohistochemical study using anti-human lysozyme antibody (Dako Kyoto, Japan) was carried 
out following the instruction manual. Electron microscopic examination was performed using JEOL 2000EX electron microscope (JEOL, Japan).

Staining intensity to anti-human lysozyme antibody of the specimen was weak in skin lesion of both period. Number of positive macrophage cells to the antibody was a bit increased in improving period than worse period. On electron microscopic examination, large parasitophorous vacuole (PV) formation of macrophages was markedly observed in both period. In worse period, PVs containing several leishmania parasites were filled with electron dense materials and surrounded by single membrane. The cell organelli of the macrophages were well developed. In contrast, PVs in improving period showed very few leishmania parasites within them and also be transparent higher than worse period, losing single PV membrane. Cytoplasm of the macrophages appeared with degeneratic change as we couldn't distinguish the cell organelli. Collagen fibers were increased between the macrophages in improving period. PV formation was unclear in LCL specimen. Macrophages showed degeneratic cytoplasm as like breaking up, with dense, dark nucleus. These findings suggested that PV appearance was likely to be correlative with disease condition and/or prognosis.

\title{
90 A CASE OF CEREBRAL SCHISTOSOMIASIS MANSONI PROBABLY INFECTED AT MACEIÓ, ALAGOAS, BRAZIL
}

\author{
YASUAKI UEDA ${ }^{1}$, TAKAYUKI KAWANO ${ }^{1}$, MASAYUKI NitTA ${ }^{1}$, Masato Kochi ${ }^{1}$, \\ Yukitaka Ushio ${ }^{1}$, Masataka Korenaga ${ }^{2}$ and Yoshinisa Hashiguchi ${ }^{2}$ \\ Department of Neurosurgery, Kumamoto University of Medical School ${ }^{1}$ and \\ Department of Parasitology, Kochi Medical School ${ }^{2}$
}

Central nervous system (CNS) may be involved in chronic schistosomiasis. It is fairly common in chronic Schistosoma japonicum infection but any schistosome species may affect CNS. Although it is rare, S. mansoni may involve CNS by embolization of eggs or ectopic migration of the adult worms. This paper demonstrated a case of cerebral schistosomiasis caused by $S$. mansoni in a 21-year-old Japanese male, who was in Maceió, Alagoas of Brazil for 3 years to study association football after graduation of junior high school. The patient presented on July 7, 1998 with headache for 3 days. Computerized tomography (CT) showed a hyperdense, enhancing lesion located in the left temporal lobe. Magnetic resoance imaging (MRI) of brain showed isointensity areas within a low intensity area on T1-weighted images and iso-intensity areas within a high intensity area on T2-weighted images. Contrast enhancement MRI revealed enhancing multipartite lesions in the same area.

Magnetic resonance angiography did not show tumor in the lesions; only a displacement was observed above the left middle cerebral artery. The patient was hospitalized with a suspected case of high grade glioma. Neurological findings were normal except slightly increased tendon reflexes. Both blood picture and blood chemistry were within normal limits. Peripheral blood eosinophil count was $5.1 \%$. The temporal lobotomy was performed and biopsy showed parasitic eggs in the tissue sections without having malignancy; hence only apparent lesions were removed. After lobotomy the patient did not declare palsy, aresthesia, or logopathy. The removed tissue was examined and diagnosed as granuloma caused by $S$. mansoni eggs. The patient was treated with praziquantel $(600 \mathrm{mg}, 3 \mathrm{~T} 3 \times 1)$. In the follow-up of the patient, no abnormality was detected in liver $\mathrm{CT}$ and no parasite egg was found in feces. 


\title{
91 APPEARANCES OF THE ECHOGENIC PATTERN OF THE NETWORK AMONG SCHOOL CHILDREN IN THE HIGHLY ENDEMIC AREA WITH SCHISTOSOMA JAPONICUM IN THE PHILIPPINES
}

\author{
Hidehiro Otake ${ }^{1,2}$, Yuichi Chigusa ${ }^{2}$, Hiroshi Ohmae ${ }^{3}$, Masataka Hayashi ${ }^{4}$, \\ EUnice IlaGan ${ }^{5}$, Masashi KiRINOKI ${ }^{2}$ and Hajime MATSUDA ${ }^{2}$ \\ Faculty of Nursing, Kure University ${ }^{1}$, Dokkyo University School of Medicine ${ }^{2}$, \\ Institutes of Basic Medical Sciences and Clinical Medicine, \\ University of Tsukuba ${ }^{3}$, Kofu City Hospital ${ }^{4}$ and \\ Schistosomiasis Control Team, Oriental Mindoro, Philippines ${ }^{5}$
}

We have not been reported for the new patient with S. japonicum after 1980 when the ultrasonographic investigation was introduced for schistosomiasis cases in Japan. It means ultrasonographic examinations were done for the treated, non-reinfected and adult cases in Japan. Several investigations have been followed in some endemic countries for adult cases since then.

All those reports had showed the adult cases of the network pattern. Therefore, the echogenic pattern of the network could appeared at the only adult patients who had kept for the long standing infection. Our investigation showed the echogenic pattern of the network on 11 young patients (9 to 14 years old) among school children at the highly endemic area in Mindanao Island, Philippines.

\section{URINE CYTOLOGY IN ENDEMIC AREA OF SCHISTOSOMIASIS HAEMATOBIUM}

\author{
Tomoharu Ohki ${ }^{1}$, Hidehiko Yamauchi ${ }^{1}$, Masanobu Anami ${ }^{2}$, \\ Masachika ISEKI ${ }^{3}$, D.K. MigWi ${ }^{4}$, F.B.M. KillikU ${ }^{4}$, N.D. MuHohO ${ }^{4}$, \\ Tatsuya Katsumata ${ }^{1}$ And YoshiKI AOKI ${ }^{1}$ \\ Department Parasitology ${ }^{1}$, Department of Pathology ${ }^{3}$, \\ Institute of Tropical Medicine, Nagasaki University, \\ Department of Pathology, Nagasaki University Hospital ${ }^{2}$ and \\ Kenya Medical Research Institute ${ }^{3}$
}

Schistosomiasis haematobium is classified as group 1 carcinogens to humans by International Agency for Research on Cancer (WHO). However only one study on the incidence of bladder cancer associated with schistosomiasis haematobium has been reported in Egypt (1980). Therefore We initiated the urine cytology to know if schistosomiasis haematobium influences the incidence of bladder carcinoma and squamous metaplasia in Kenya.

The urine cytology was done from the individuals who were all 20 years old and above from an endemic area of Tserezani where no antibilharzia control measures have been carried out and from a non-endemic area of Kiambu. For the cytological diagnosis, the Papanicolau classification (class I to class V) was adopted. In Tserezani the urine examination for Schistosoma haematobium was also carried out by nucleopore filtration method.

In Tserezani, the prevalence and intensity of infec- tion were $41.6 \%$ and 1.1 eggs per $10 \mathrm{~m} l$ of urine in 261 individuals examined (74 males and 187 females, mean age $37.4 \pm 14.5$ year old). Among them 4 cases were diagnosed by urine cytology as class III and 7 as class II. Nine out of these 11 cases were accompanied with squamous metaplasia. All the cases were females below the age of 50 years old. In five of the nine cases the eggs were identified in the urine.

In Kiambu, all were diagnosed as class I without any cases of squamous metaplasia in 294 individuals examined (78 males and 216 females, mean age $46.4 \pm$ 17.6 years old).

Thirty three cases (12.6\%) in Tserezani and 16 cases $(5.4 \%)$ in Kiambu were suspected urinary tract infection by the presence of neutrophilia in the urine.

In conclusion, the cases with squamous metaplasia and the suspected cases with urinary tract infection were found to be significantly higher from the endemic area than those from the non-endemic area $(p<0.05)$. 
These results suggest that schistosomiasis haematobium might influence the incidence of squamous metaplasia and urinary tract infection.

\title{
93 VACCINATION OF DOMESTIC PIG WITH RECOMBINANT PARAMYOSIN AGAINST SCHISTOSOMA JAPONICUM IN CHINA
}

\author{
Kenji Hirayama ${ }^{1}$, Takeshi Nara ${ }^{2}$, HongGen Chen $^{3}$, Xianjun ZenG ${ }^{3}$, \\ Masao Satoh ${ }^{1}$, S. Zhang ${ }^{3}$ and Somei KoJima ${ }^{4}$ \\ Department of Medical Zoology, Saitama Medical School ${ }^{1}$, \\ Department of Parasitology, Juntendo University School of Medicine ${ }^{2}$, \\ Jiangxi Provincial Institute of Parasitic Diseases ${ }^{3}$ and \\ Department of Parasitology, Institute of Medical Science, \\ The University of Tokyo ${ }^{4}$
}

Paramyosin (PM), a myosin-like protein is a major antigen on Schistosoma japonicum $(\mathrm{Sj})$. We reported that passive transfer of a monoclonal $\operatorname{IgE} \mathrm{SjE} 18 \varepsilon .1$ which recognizes PM of Sj (SJPM), partially protected mice from challenge infection. In the present study, we developed an experimental model system of schistosomiasis japonica with domestic pigs in China and used it for the evaluation of vaccination with recombinant SJPM (rSJPM). Sixteen-week-old pigs were successfully infected by dermal penetration of 120 cercariae of a domestic strain of $\mathrm{Sj}$ (50-60\% worm recovery 11 weeks after challenge).

The pigs vaccinated with $400 \mathrm{UV}$ attenuated cercariae showed a reduction of worm recovery $(49-53 \%, \mathrm{p}<$ 0.001). The experimental groups were immunized intradermally with rSJPM and alum or TiterMax and were partially protected against the challenge infection (32-35\% reduction).

\section{ANALYSIS OF THE EGGSHELL PRECURSOR PROTEIN OF SCHISTOSOMA JAPONICUM USING SYNTHETIC PEPTIDES AND ANTISERA AGAINST THEM}

\author{
Hiromu SugiYama And Masanori KaWANAKA \\ Department of Parasitogy, National Institute of Infectious Diseases
}

We have isolated a cDNA clone encoding part of the $34 \mathrm{kDa}$ eggshell protein of Schistosoma japonicum from an adult female library with a rabbit antiserum raised against the $34 \mathrm{kDa}$ female worm fraction (Int. J. Parasitol., 27, 811, 1997). This clone, designated Sj23A, contains an open reading frame of 230 nucleotides coding for a polypeptide of 76 amino acids. According to the deduced amino acid sequence of $\mathrm{Sj} 23 \mathrm{~A}$, overlapping peptides were synthesized. They represented the following amino acid residues of the deduced polypeptide: 7 to 26 (peptide 1), 10 to 29 (pep. 2), 19 to 38 (pep. 3), 27 to 46 (pep. 4), 29 to 48 (pep. 5), 38 to 57 (pep. 6) and 45 to 64 (pep. 7). An extra cysteine residue was added to the amino terminus of each synthetic peptide. Each of the synthetic peptides was tested by ELISA for its binding ability to the anti-34 $\mathrm{kDa}$ female protein antiserum, which was employed to screen $\mathrm{Sj} 23 \mathrm{~A}$. Of the 7 peptides, peptide 4 showed the highest binding activity to the antibody.

Antisera against the peptides were produced by hyperimmunization of rabbits. With the antiserum against peptide 4 , the band of $34 \mathrm{kDa}$ was recognized in the female worm extracts by SDS-PAGE and immunoblotting analysis. By immunohistochemical analysis, a positive reaction was observed in the vitelline cells of the vitelline glands of the female worms. These data indicated that the antibody against the synthetic peptide (peptide 4) is available to analyze the eggshell gene product, namely, the eggshell precursor protein of $S$. japonicum. 


\title{
95 MOLECULAR PHYLOGENETIC RELATIONSHIPS BETWEEN THE S. INDICUM GROUP AND OTHER SPECIES OF SCHISTOSOMA
}

\author{
TAKeshi Agatsuma ${ }^{1}$, MoRitoshi IWAGami ${ }^{2}$, R.P.V.J. RajaPaksE ${ }^{3}$ AND \\ M.M.H. MONDAL ${ }^{4}$ \\ Department of Environmental Health Science, Kochi Medical School ${ }^{1}$, \\ Department of Biological Resource Science, \\ Obihiro University of Veterinary Medicine and Agriculture ${ }^{2}$, \\ Department of Veterinary, Para-Clinical Studies, \\ University of Perageniya ${ }^{3}$ and \\ Department of Veterinary Medicine, Bangladesh Agricultural University ${ }^{4}$
}

Traditionally, Schistosoma species have been arranged in groups based on egg morphology and the genus or family of intermediate host. The S. japonicum group have eggs with a minute spine and develop in the operculate snails, like the Oncomelania species. On the other hand, species of the $S$. mansoni group has eggs with a lateral spine and utilize pulmonate snails, Biomphalaria, while the $S$. haematobium group has eggs with a terminal spine and develop in the genus, Bulinus. On the other hand, members of the $S$. indicum group (S. in dicum, S. spindale, S. nasale and S. incognitum) develop in snails of Planorbiidae and Lymnaeidae, having subterminal-spined eggs. In the present paper, phylogenetic relationships between members of the $S$. indicum group and other Asian species of Schistosoma was examined using DNA sequence data from part of the mitochondrial cytochrome $\mathrm{C}$ oxidase subunit I (COI) gene and the second internal transcribed spacer (ITS2) of the ribosomal gene repeat.

The African schistosomes tend to form well resolved groups on the tree, strongly supported by bootstrapping, and the isolates of S. japonicum always form a single clade. In all analyses, $S$. malayense is associated with S. mekongi rather than with S. japonicum (Blair et al., 1997). On the other hand, S. sinensium was placed within the Asian groups, and positioned to near the root of the tree. Tree analysis also showed that $S$. incognitum appeared as the sister group to all remaining species, and surprisingly all other three species, S. indicum, $S$. spindale and $S$. nasale were included into the Arican cluster. The present study suggested that Asian species of Schistosoma comprised of several genetically distant groups which may have migrated into the Asian continent at the different periods as well as at the different ways.

\section{A CASE OF ELEPHANTIASIS CAUSED BY PRIMARY LYMPHEDEMA, DIFFERENTIAL DIAGNOSED FROM FILARIASIS}

\author{
Mikimasa Noguchi ${ }^{1}$, Chie Kan ${ }^{1}$, Mitsuhiro Kamiyosihara ${ }^{2}$, \\ HisANORI YAJIMA ${ }^{3}$, OSAMU ISHIKAWA ${ }^{4}$ AND MAMORU SUZUKI ${ }^{5}$ \\ Division of Dermatology ${ }^{1}$, Division of Cardiovascularsurgery ${ }^{2}$ and \\ Division of Urology ${ }^{3}$, Maebashi Red Cross Hospital, \\ Department of Dermatology ${ }^{4}$ and Department of Parasitology ${ }^{5}$, \\ Gunma University School of Medicine
}

A 32 -year-old man with elephantiasis caused by primary lymphedema was reported, who presented with 14 -years history of severe edema in both of his legs. His past history included protenuria at the age of 10 , but his family history was noncontributory. He has no experience to go abroad or extra-prefecture. He had been diagnosed as nephrosis and treated by oral predonisolone without any improvement. The patient admitted our hospital for further examinations on June 17, 1998.

On physical examination, elephantiasis is remarkable in both of his legs. The laboratory tests revealed slight protenuria, but white blood cell and eosinophil count within normal, as were results of screening of hepatic and renal function. Serologically, antififilarial antibodies were negative and pathological findings 
revealed no filaria. The patient was diagnosed as having primary lymphedema, and treated by surgical excision. Elephantiasis occure not only by filariasis but also by another lymphedemic disorders. Primary lymphedema is one of the differential diagnosis from filarial elephantiasis, especially in the epidemic area. We, clinitian, should keep this in our mind.

\title{
97 EFFECT OF PF1022A ON MONGOLIAN GIRBILES INFECTED WITH BRUGIA PAHANGI
}

\author{
Masumi Shimizu-Suganuma ${ }^{1}$, Kazuhiro Shichinohe ${ }^{1}$, Katsuya Haga ${ }^{2}$, \\ Tetsuo IEdoKoro ${ }^{2}$, Setsuko Tsukidate ${ }^{2}$ And Koichiro Fujita ${ }^{2}$ \\ Department of Laboratory Animal Sciences, Nippon Medical School ${ }^{1}$ and \\ Department of Medical Zoology, Faculty of Medicine, \\ Tokyo Medical and Dental University ${ }^{2}$
}

PF1022A is a new anti-nematode drug isolated from a microflora on leaves of plant, which has a cyclic depsipeptide structure. The substance has a superior action against various intestinal nematodes and some effects were reported on Angiostrongylus costaricensis, A. cantonensis and microfilariae of Brugia pahangi. We investigated effect of oral administration of PF1022A on the third- $\left(\mathrm{L}_{3}\right)$ or the forth-stage larvae $\left(\mathrm{L}_{4}\right)$ of filaria using Mongolian gerbils infected with B. pahangi. Male gerbils were infected subcutaneously into the inguinal region with $100 \mathrm{~L}_{3}$ of $B$. pahangi. The animals were orally administered at doses of 10,20 or $100 \mathrm{mg} / \mathrm{kgBW} /$ day PF1022A with oral cream from 7 to 9 days after infection.

Numbers of microfilariae and of eosinophils in blood were lower in the gerbils treated with 20 and 100 $\mathrm{mg} / \mathrm{kg}$ than the infected control animals. Body weight loss was observed in the gerbils of infected control and $10 \mathrm{mg}$, but not in those of 20 and $100 \mathrm{mg} / \mathrm{kg}$. Adult worm recovery rate at 25 week after infection was significantly lower in the $100 \mathrm{mg}$ group than in the infected control. These results suggest that the oral cream of PF1022A is effective on $\mathrm{L}_{3}$ or $\mathrm{L}_{4}$ and suppress body weight loss induced by filarial infection. PF1022A has potential activity against filariasis.

\section{PREVALENCE OF INTESTINAL PARASITIC INFECTIONS AMONG THE INHABITANTS IN SANTO DOMINGO, DOMINICAN REPUBLIC}

\author{
Kazutoshi Nakashima ${ }^{1}$, Hideo Hasegawa ${ }^{2}$ And Akira Miyata ${ }^{2}$ \\ Department of Microbiology ${ }^{1}$ and Department of Biology ${ }^{2}$, \\ Oita Medical University
}

[Materials and Methods] Prevalence study of intestinal parasites was conducted among people who live in Santo Domingo (SD), Dominican Republic from October 1995 to August 1996. We visited them house to house to collect facal specimens, and also conducted questionnaires concerning income, drinking water and others related to sanitation. We also conducted the same study in two primary schools in SD. Kato-Katz method and MGL method were performed for detecting intestinal parasites from stools. We collected 1,070 fecal specimens among 1,635 persons who replied the questionnaire. All specimens were microbiologically examined, and results were given back to the people with free therapeutic drugs if needed. Among them, we analyzed 783 samples, of which information of inhabitation was available, and further in comparison with data obtained from people living in the urban-type slum La Cienaga (LC) in SD under the previous study (Hasegawa et al., 1995).

[Results] We categorized people into two groups such as higher class $(\mathrm{CH})$ and lower class (CL) depending upon the area of their inhabitation. In $\mathrm{CH}$, age of the people was $34.5 \pm 2.1$ (mean $\pm \mathrm{SD}$ ), number of family members was $6.0 \pm 2.1$ and median of monthly income of 
home was US $\$ 692$. In CL, they were $21 \pm 17.2,6.4 \pm 3.1$, 230, respectively.

[Discussion] Soil-transmitted helminths and watertransmitted protozoa were highly prevalent among the inhabitants. The prevalence of the helminths was related to people's inhabitation. On the other hand, no obvious tendency was observed in the prevalence of water-transmitted protozoa, therefore contamination of the protozoa seemed to be widely spreaded. Although routine anti-parasitic medication was conducted in the schools where we studied, students living in LC were more likely to be infected with helmintos. Comprehensive approach to control parasitic infection in SD might be needed.

\title{
100 MONITORING MORBIDITY CONTROL OF SOIL TRANSMITTED NEMATODES IN ZANZIBAR-TANZANIA
}

\author{
H.M. Chwaya ${ }^{1,2}$, R.J. Stoltzfus ${ }^{3}$, M. Albonico 4 , J. Tielsch ${ }^{3}$, \\ K.S. Alawi ${ }^{2}$, A. Montresor ${ }^{5}$ and Savioli Lorenzo \\ Department of Parasitology, Institute of Tropical Medicine, \\ Nagasaki University ${ }^{1}$, \\ Ministry of Health, Zanzibar, Tanzania ${ }^{2}$, \\ Center for Human Nutrition, The Johns Hopkins School of Public Health, USA ${ }^{3}$, \\ Ivo De Carneri Foundation, Italy ${ }^{4}$ and \\ SIP Unit, Division of Control Tropical Diseases, WHO, Geneva ${ }^{5}$
}

In Zanzibar morbidity due to soil transmitted nematodes is recognized as an important public health problem. A community survey $(\mathrm{N}=2,200)$, undertaken on Pemba island, one of the two major islands forming archipelago of Zanzibar showed the prevalence of $A s$ caris lumbricoides, Trichuris trichiura and hookworm infection to be $48 \% 76 \%$ and $61 \%$, respectively. Both prevalence and intensity were found to peak in school age-group. This was also further confirmed by a school survey $(\mathrm{N}=3,605)$ which showed the prevalence of $A$. lumbricoides, $T$. trichiura and hookworm infection to be $72 \%, 96 \%$ and $94 \%$, respectively. The school survey showed that $99 \%$ of the children were infected with at least one of the three major soil transmitted nematodes prevalent in Zanzibar. The documented associated morbidity of the infection include growth faltering, iron deficiency anaemia and poor cognition as manifested by low level of school performance and absenteeism.

Community-based intervention programmes aimed at reducing morbidity by regular chemotherapy of the high risk groups have now become of priority in areas where these infections are endemic.

We report the results of twelve months follow up of school-based deworming programme focusing on hookworm infection in iron deficiency and anaemia in children where the incidence of severe anaemia was reduced by $39 \%$ prevalence of iron deficient erythropoises was reduced by $16 \%$ that of depleted iron stores by $20 \%$ and non-wasting and stunting observed in these children improved by $16 \%$ and $20 \%$, respectively.

In this environments of intense helminth transmission $3 \times /$ year deworming with single dose mebendazole is necessary to achieve the best impact of iron status. The control of iron deficiency in Zanzibar will require the integration of multiple interventions of which deworming is one essential component of this strategy and that monitoring of periodic chemotherapy has provided evidence of the short term cost effectiveness of the school-based deworming programme. However, long term monitoring is essential for the purpose of targeting sustainability and adjusting control strategies. 


\title{
101 REVIEW OF CURRENT 139 LEPROSY PATIENTS AT RYUKYU UNIVERSITY HOSPITAL AND A CASE REPORT OF BORDERLINE LEPROMATOUS LEPROSY WHO SHOWED ATYPICAL CLINICAL FINDINGS
}

\author{
Atsushi Hosokawa, Atsushi Takamiyagi, Hiroshi Uesato and Shigeo Nonaka \\ Department of Dermatology, Faculty of Medicine, University of The Ryukyus
}

The aim of our presenting study is to evaluate the paients with leprosy visited to Ryukyu University Hospital, located at Okinawa Prefecture, where the leprosy had show gradually epidemilogicaly improvements over the past 15 years (1982-1996).

The number of each type of leprosy patients examined at our hospital during the past 15 years were as follows; indeterminate leprosy, 11 (8.1\%); tuberculoid leprosy (TT), 48 (35.6\%); borderline tuberculoid leprosy, 36 (26.7\%); middle borderline leprosy, 14 (10.4\%); borderline lepromatous leprosy (BL), 10 (7.4\%); lepromatous leprosy, 13 (9.6\%); purely neural type, 2 and primary lesion, 1 . Though number of new patients and percentage of TT has decreased, relatively a large number of middle-aged cases was detected.
The patient was a 47-year-old female. She had been suffered from aortitis syndrome and was treated with Prednisolone $15-30 \mathrm{mg} /$ day for 20 years. Since 7 years, a reddish freckle appeared on her forearm. The lesion was diagnosed as dermatitis and treated with steroid ointment for 5 years. At the time of her visit to our hospital, she was diagnosed as BL. This case was considered to be iatrogenic BL which had been downgraded from TT and showed atypical cutaneous changes by the treatments with steroid hormone.

From the results obtained, it was suspected that small number of leprosy patients may still be seen in Okinawa in the future. In addition, such misdiagnosed case as above mentioned BL may be encountered because this disease became very rare in Japan.

\section{WHO LEPROSY ELIMINATION PROGRAM IN FEDERATED STATES IN MICRONESIA}

\author{
JUNyA TAKASHIMA AND OHICHIROU KOBORI \\ International Medical Center of Japan
}

The Federated States of Micronesia has one of the highest prevalence rate in the world despite implementation of multidrug therapy (MDT) with high coverage since 1983 onwards. With this situation, a two-year project on leprosy elimination was launched in 1996 and was completed. The writer worked for the first round of the project as a WHO consultant.

[Objectives] The objective is to reduce the prevalence rate in the Federated States of Micronesia to less than one case per 10,000 population by the year 2000 .

[Methods] The project includes two rounds of total population screening for leprosy case detection as intensive case finding, to provide MDT to all cases and propose preventive therapy to all non-cases, which consists of a combination of rifampicin, ofloxacin and minocycline (ROM) a single dose a year for two years. After completion of the project, all cases detected during 1996-1998 were reviewed.

[Results] 75,886 people (72\% of the total population) and 77,199 people $(73 \%)$ were screened during the first round and second round respectively. The preventive therapy was administered to 73,516 people (70\%) and 75,865 people $(72 \%)$ in each round. The coverage of people receiving 2 doses of preventive therapy was $54 \%$ of the total population. During the first round, a total of 322 new cases was detected of which 67 (21\%) were MB and $116(36 \%)$ were below 15 years. During the second round, a total of 80 new cases were detected of which 38 (47\%) were single lesion, 28 (35\%) were MB and 31 (39\%) were below 15 years, which indicated a $75 \%$ reduction from the first to the second round. Between 1996 and 1997 a total of 488 cases completed MDT treatment, as consequence, the prevalence rate dropped from 41 per 10,000 in 1996 to 15 per 10,000 in 1997. Preliminary data of 1998 indicates a further reduction of prevalence down to 8 per 10,000 .

[Conclusions] This project made a contribution to the sharp decline of the prevalence rate in Federated States of Micronesia. This was also due to the implementation of the new WHO simplified MDT regimens, which involved one single dose of ROM for single skin lesion and the shortening to 12 months of the treatment for $\mathrm{MB}$ 
cases. However, due to the geographical and communication constraints, the case holding is still poor. Further management should be reinforced.

\title{
103 SOCIAL IMPLICATION OF LEPROSY CONTROL IN MYANMAR WITH AN EMPHASIS ON THE GOAL OF ELIMINATION
}

\author{
S. BARUA ${ }^{1}$, S. WAKAI ${ }^{2}$, T. ShWE ${ }^{3}$ AND TAKUSEI UMENAI ${ }^{1}$ \\ Department of Health Policy and Planning ${ }^{1}$, \\ Department of Community Health, Faculty of Medicine $^{2}$, \\ The University of Tokyo and \\ National Leprosy Elimination Program, Department of Health, Yangon, Myanmar ${ }^{3}$
}

Myanmar (population; 46 million) is significant in leprosy endemic and included by WHO in a list of the top 16 major leprosy endemic countries. Multi Drug Therapy (MDT) was introduced in Myanmar in 1988. MDT coverage over the registered cases sharply increased from less than $20 \%$ in 1988 to $100 \%$ in 1995 and the Reg. PR was reduced from 39.9 in 1988 to 2.91 per 10,000 population in 1997.

The present study was undertaken to investigate: public health and social implications of the loprosy control program of the country. The study was focused on social-factors influencing community-based case detection such as awareness on leprosy, knowledge and attitude towards the disease, existing social stigma of the community leaders and the patients. 3 Townships were selected by the stratified random samplingas high, medium and low leprosy endemic areas according to the 1997 Reg. PR of leprosy and interviewed all newly diagnosed and registered cases (284) from January to December 1997 and one or more community leaders (156) from each village with leprosy case.

The study showed that 1 ) the higher the knowledgescore on leprosy, the more cases are diagnosed by passive case detection method to diagnose the patients interviewed; 2) the MDT of leprosy infection-load and showed its epidemiological implication as well as its impact on public health of the country. Increasing knowledge, and awareness, improved attitude and reduced social stigma towards leprosy among the interviewed patients and the community leaders reflect in the increasing trend or passive case detection proportion among the new cases detected.

Based on these findings, Myanmar may formulate a national target with a long-term action-plan that would be necessary by considering the long incubation period of the disease.

\section{CLINICAL FEATURES OF 44 CASES OF DENGUE VIRUS INFECTION AMONG OVERSEAS TRAVELERS IN JAPAN}

\author{
IChiro Itoda ${ }^{1}$, Gohta Masuda ${ }^{1}$, Atsushi Ajisawa ${ }^{1}$, Akifumi Imamura ${ }^{1}$, \\ Masayoshi Negishi ${ }^{1}$, Ken-ICHIRO YAMAdA ${ }^{2}$, SAdAO Yabe ${ }^{2}$, \\ TOMOHIKO TAKASAKI ${ }^{2}$ AND ICHIRO KURANE ${ }^{2}$ \\ Department of Infectious Diseases, \\ Tokyo Metropolitan Komagome Hospital ${ }^{1}$ and \\ National Institute of Infectious Diseases ${ }^{2}$
}

[Object] To determine the clinical features of imported dengue virus infections in Japan.

[Method] We investigated 44 cases of imported dengue virus infection who were admitted to Tokyo Metropolitan Komagome Hospital between 1985 and 1998.

[Cases and Results] We identified 44 cases of ser- ologically confirmed dengue virus infectiou. 33 cases were male and 11 were female. Age distribution was 18 to 62 years old (mean age 32 years old). Subsequent to 1991, we applied a polymerase chain reaction for each cases to determine its subtype. We identified subtypes in 8 cases ( 1 case of DEN1, 5 cases of DEN2, 1 case of 
DEN3, 1 case of DEN4). 13 cases were presumed infected in Thailand, 10 cases in India, 7 cases in Indonesia, 4 cases in Philippines. Nearby all cases were presumed to originate in Asia, with the majority therein from Southeast Asia. Clinical manifestations revealed fever $(100 \%)$, chills $(40 \%)$, headache $(88 \%)$, retoroorbital pain $(29 \%)$, myaliga (71\%), profuse sweating (56\%), diarrhea $(53 \%)$, skin rash $(82 \%)$.

Laboratory examinations revealed thrombocytopenia (between $10,000-298,000 / \mu l$, mean at $92,000 / \mu l$, leukocytopenia (between 1,000 to $8,500 / \mu l$, mean at $2,730 / \mu l$ ), elevation of AST and LDH levels. One case was considered as dengue haemorrhagic fever Grade II according to WHO dengue haemorrhagic fever grading severity.

[Conclusion] Dengue fever should be taken into differential diagnosis when we see patients with fever among travelers from tropical areas in addition to malaria, typhoid fever, paratyphoid fever etc. Lacking typical symptoms (i.e. retroobital pain), we should consider dengue virus infection when thrombocytopenia, leukocytopenina, and elevation of AST and LDH levels are seen.

\title{
105 THE CURRENT STATUS OF AEDES ALBOPICTUS DISTRIBUTION IN NORTHEAST HONSHU, JAPAN
}

\author{
Takeshi Kurihara, Naoko Nihei and Mutsuo Kobayashi \\ Department of Entomology, National Institute of Infectious Diseases, Japan
}

The published records of Aedes albopictus in the northeast of Honshu island, Japan, were from Taira (Ishii et al., 1944), Fukushima (Ara, 1949), Niigata (Omori, 1958) and Sendai (Kamimura, 1968) cities. We have examined the status of distribution of this mosquito at 26 cities in northern Japan since 1993 (Kurihara et al., 1997), and subsequently extended the survey to cover 26 cities located in northeast Honshu. The survey focused on finding the larvae and biting adults in districts which were densely populated and also where there were many water-filled containers. The temperature data were obtained from the Meteorological Agency.

As of September 1998, Ae. albopictus was found at 22 out of the 52 cities examined. The mosquito was also found in abundance in the cities initially recorded. Then 18 new locations were identified, namely, Honjou, Yonezawa, Furukawa, Sakata, Aizuwakamatsu, Kitagata, Nagano, Matsumoto, Ueda, etc. It was suggested that the first three cities which are located between latitude $37^{\circ} 50^{\prime} \mathrm{N}$ to $39^{\circ} 24^{\prime} \mathrm{N}$ constitute the northermost front of this mosquito distribution at present. The mean annual temperature of these 22 cities ranged from 10.7 to $13.5^{\circ} \mathrm{C}$ : the daily mean January temperature ranged from -1.2 to $3.1^{\circ} \mathrm{C}$ and the daily minimum January temperature ran- ged from -6.1 to $-0.5^{\circ} \mathrm{C}$. It is apparent that such cold winter conditions do not deter the establishment of $A e$. albopictus. The number of days of daily mean temperature under $10^{\circ} \mathrm{C}$, that is, the putative threshold temperature for mosquito development, was observed to be 143 to 177 in a year.

However, no $A e$. albopictus was found at the other 30 cities. The range of annual mean temperature, daily mean January temperature and daily minimum January temperature of these cities were 7.6 to $12.0,-4.3$ to -1.0 and -9.5 to $-4.5^{\circ} \mathrm{C}$, respectively. The number of days of daily mean temperature of less than $10^{\circ} \mathrm{C}$ was from 169 to 224 in a year. In respect of the climatic conditions no significant difference is at present noted in the presence or absence of Ae. albopictus. However, some cities which are now free of $A e$. albopictus, are potentially at high risk of future colonization in view of the morquito's ability to expand their distribution and the improved means of transportation. Of the 30 cities, 10 cities including Nikko, Karuizawa, Komoro etc., are free of the mosquito although they are located at around $37^{\circ} \mathrm{N}$ or farther south. These cities are located in mountainous areas at 400 to $950 \mathrm{~m}$ above sea level, and the population density is less than $120 / \mathrm{km}^{2}$. 


\title{
106 ANALYSIS ON CHEMOKINE AND VEGF IN SERA FROM PATIENTS WITH DENGUE FEVER (DF)/DENGUE HEMORRHACGIC FEVER (DHF) IN PHILIPPINES
}

\author{
TAKayoshi NagaO ${ }^{1}$, Kazunori Oishi ${ }^{1}$, Futoshi Hasebe ${ }^{2}$, Kouichi Morita ${ }^{2}$, \\ AKIRA IGARASHI ${ }^{2}$ AND TSUYOSHI NAGATAKE ${ }^{2}$ \\ Department of Internal Medicine ${ }^{1}$ and Department of Virology ${ }^{2}$, \\ Institute of Tropical Medicine, Nagasaki University
}

\begin{abstract}
[Objective] To determine the involvement and roles of chemokine and vascvlar endothelial growth factor (VEGF), which is known as vascular permeability factor, in sera from patient with $\mathrm{DF} / \mathrm{DHF}$.

[Methods] At the St. Lukes Medical Center of San Lazaro Hospital in Phillippines, we enrolled patients with Dengue viral infection confirmed by the methods of IgM ELISA or RT-PCR using serum sample. Subjects were classified into dengue fever (DF) and dengue hemorrhagic fever (DHF) by the criteria of WHO. The chemokine (IL-8 and MIP- $1 \alpha$ ) and VEGF in the sera of $\mathrm{DF} / \mathrm{DHF}$ patients and healthy volunteers (HV) were measured by ELISA and each value were compared and statistically analysed.

[Results] The value of mean IL-8 in sera from HV, DF and DHF were $0,692,805(\mathrm{pg} / \mathrm{m} l)$, the value of mean
\end{abstract}

MIP- $1 \alpha$ were $0,1,880,2,006(\mathrm{pg} / \mathrm{m} l)$ and the value of mean VEGF were 9, 62, $75(\mathrm{pg} / \mathrm{m} l)$, respectively. The value of both chemokine and VEGF in DF/DHF patients were significantly higher than those in HV. There was no difference in serum levels of chemokine and VEGF between DF and DHF.

[Conclusions] We demonstrated significant increases of IL-8, MIP- $1 \alpha$, and VEGF in sera from DF/DHF, compared with sera from HV. None of these mediators in sera, however, correlated with disease severity. These results may be due to inaccuracy of grading in DHF in Phillippines. Further study will be required to determine if these mediators correlate with disease severity under careful clinical diagnosis and grading in DHF.

\section{LABORATORY DIAGNOSIS OF DENGUE VIRUS INFECTION -EVALUATION OF DIAGNOSTIC METHODS BASED ON THE DAY OF DEFERVESCENCE-}

\author{
Ken-IChiro Yamada ${ }^{1}$, Tomohiko Takasaki ${ }^{1}$, Sadao Yabe ${ }^{1}$, \\ MASARU NAWA ${ }^{2}$ AND ICHIRO KURANE ${ }^{1}$ \\ Department of Virology 1, National Institute of Infectious Diseases ${ }^{1}$ and \\ Department of Microbiology, Saitama Medical School ${ }^{2}$
}

Dengue virus infections are a major public health ploblem in many tropical and sub-tropical countries of the world. Dengue is occasionally imported by travelers who visit tropical areas and become infected with dengue virus. Laboratory diagnosis is necessary for confirming the diagnosis of dengue. Detection of specific IgM by IgM-capture enzyme-linked immunosorbent assay (ELISA) and of dengue virus genome by reverse transcriptase polymerase chain reaction (RT-PCR) has recently been used for laboratory diagnosis of dengue.

In the present study, we tested serum specimens from dengue-suspected Japanese cases, by IgM-capture ELISA, RT-PCR, HI and virus isolation. Serum sam- ples collected before or on the day of defervescence were positive by RT-PCR, and there were no PCRpositive samples which were obtained after the day of defervescence. IgM-capture ELISA was positive as early as 4 days after onset of illness, and all the samples but one were IgM-positive when collected on after onset of illness 5 or later. We, therefore, recommend to perform both RT-PCR and IgM-capture ELISA, irrespective of the stage of dengue illness. Combination of RT-PCR and IgM-capture ELISA increases the ability to diagnose dengue virus infection, even when only single serum specimen is available. 


\title{
108 EFFICACY OF DENGUE CONTROL USING PLYSET NET DURING AN EPIDEMIC IN VIENTIANE, LAO PDR
}

\author{
B. Phommasack ${ }^{1}$, M. Saito ${ }^{2}$, T. Sisouk 3 , K. Bounlu ${ }^{3}$, \\ S. InsisiengmaY ${ }^{3}$, Y. MAKINO ${ }^{4}$, T. ITOH ${ }^{5}$ AND T. FukUnAGA ${ }^{2}$ \\ Department of Public Health, Vientiane Municipality ${ }^{1}$, \\ Faculty of Medicine, University of the Ryukyus ${ }^{2}$ \\ Center of Laboratory and Epidemiology, Lao People's Democratic Republic ${ }^{3}$, \\ Oita Prefectural Institute of Health and Environment ${ }^{4}$ and \\ Sumitomo Chemical Co. LTD. ${ }^{5}$
}

Olyset Net is a new type of polyethylene net incorporated with insecticide, permethrin during manufacturing. A field study was carried out to evaluate the efficacy of dengue control using the Olyset Net in Xaisettha district, one of dengue epidemic urban areas in Vientiane Municipality, Lao PDR, by hanging down or covering at any opening of all houses in a village in May, 1996. Aedes aegypti population decreased (adult density index 1.00 to 0.00 , larval House Index 12.00 to 3.13, Breteau Index 16.00 to 3.13) after setting up the Olyset Net and kept low level until the end of monitoring, December, 1996. In the year of 1996, dengue fever (DF) /dengue hemorrhagic fever (DHF) epidemic occurred in Xaisettha district with 441 cases and the highest morbidity rate (597.5) in all districts in Vientiane.
In the Olyset Net treatment village no $\mathrm{DF} / \mathrm{DHF}$ case was reported while 14 cases including 3 DHF cases were reported in the control village $(6 \mathrm{~km}$ away from the treatment village, in Xaisettha). The sero-conversion rate of anti-flavivirus $\mathrm{IgG}$ antibody before and after epidemic season in children in the treatment village was significantly less than that of the control village. Thus dengue virus transmission was interrupted by Olyset Net during dengue epidemic. The interview survey showed that the community accepted well the Olyset Net as a simple and comfortable method for dengue control. The results of this study indicate that Olyset Net should be effective and applicable in other villages of Lao PDR and possibly elsewhere.

\section{COMPARATIVE SEQUENCE ANALYSIS OF TYPE 2 DENGUE VIRUS STRAINS FROM PATIENTS WITH DIFFERENT CLINICAL SEVERITIES AND INFECTION TO PRIMARY CULTURE HUMAN PERIPHERAL BLOOD MONONUCLEAR CELLS}

\author{
Akira Igarashi, Basu Devu Pandey, Beti Ernawati Dewi Soemanto, \\ Futoshi Hasebe and Kouichi Morita \\ Department of Virology, Institute of Tropical Medicine, \\ Nagasaki University
}

In order to obtain direct evidence for the virulent virus theory regarding the pathogenesis of dengue hemorrhagic fever (DHF), nucleotide and deduced amino acid sequences were analyzed on 19 strains of dengue type 2 (D2) virus isolated from patients with different disease severities, in Nakhon Phanom, Northeast Thailand in 1993. The results were compared with clinical symptoms and serological response of the patients. Three representative strains were infected to primary culture human peripheral blood mononuclear cells (PBMC) obtained from 3 different donors to measure infection rate as well as cytokine levels released into the culture supernatant.
Amino acid sequence analysis classified 19 isolates into 3 subtypes. A single strain of subtype I uirus was isolated from a dengue shock syndrome (DSS) case showing secondary type antibody response. Thirteen strains of subtype II viruses were isolated from DHF cases showing secondary type antibody response, whereas two strains of subtype II viruses were from mild dengue fever (DF) case showing primary type antibody response. On the other hand, all 3 strains of subtype III viruses were isolated from mild DF patients, whose antibody response was primary type for 2 cases and secondary type for a remaining case, respectively. Infection rate of the virus to human PBMC was differ- 
ent from donor to donor, but highest for the subtype I, followed by subtype II, and lowest for subtype III virus, for each donor. Similar trend was observed for some cytokine levels ( $\mathrm{TNF}$-alpha and $\mathrm{IL}-2$ ) released into culture supernatant of infected PBMC.

The results indicated that both molecular structure of the virus and serological response of the patients determines pathogenesis of DHF indicating following possibilities. (1) Secondary infection with subtype I virus could be very severe (DSS). (2) Secondary infection with sybtype II virus could be quite severe (DHF), but its primary infection could be mild (DF). (3) Infection with subtype III virus could be mild (DF) irrespective of the serological response, either primary or secondary. These possibilities should be confirmed with other virus strains isolated in different epidemic areas during different epidemic seasons.

\title{
110 MOLECULAR ANALYSIS OF DIFFERENT INFECTIVITY OF DENGUE 1 VIRUS STRAINS IN VARIOUS CELL LINES
}

\author{
HASANUdDin ISHAK $^{1,2}$, KIYOSHI KamimuRA ${ }^{2}$ And Tsutomu TAKEgami ${ }^{1}$ \\ Medical Research Institute, Kanazawa Medical University ${ }^{1}$ and \\ Department of Biodefence Medicine, Faculty of Medicine, \\ Toyama Medical and Pharmaceutical University ${ }^{2}$
}

Dengue virus causes a lot of the dengue fever in tropical area. The infection with dengue virus sometimes leads to serious cases like hemorrhagic fever and dengue shock syndrome. The mechanism of such severe diseases is still unknown, although two possibilities, i.e. immune enhancement and the viral virulence are thought. Here we started to compare the difference in viral virulence between two strains of dengue type 1 . We used two dengue type 1 strains, A88 (isolated in Indonesia) (Fujita et al., 1997) and Mochizuki (isolated in Nagasaki, Japan) (Kimura and Hotta, 1943).

For the virus multiplication, $\mathrm{C} 6 / 36$ (mosquito cells), Vero (African green monkey kidney cell line) and HepG2 (human hepatoma cell line) were used. The viral growth rate and yield of A88 strains in mosquito
C6/36 cells were almost same as those of Mochizuki strain viruses. However, when we used mammalian cells (Vero and HepG2), the multiplication of A88 were 100 times lower than that of Mochizuki. In addition, the infectivity of A88 strains was decreased after the storage at $-80^{\circ} \mathrm{C}$ or heat treatment at $50^{\circ} \mathrm{C}$. These results suggest that the envelope (E) protein of A88 seems to be sensitive against temperature. To know the variation of A88 E protein, we analyzed the sequence. RT-PCR using specific primers and direct sequencing analysis were performed. Nucleotide sequencing analysis indicated that 19 amino acids of $\mathrm{E}$ protein of A88 strain were substituted. Now, the study on the difference in virulence between both strains is undertaken.

\section{THE PRESENT CONDITION OF MEDICAL CARE AND MANAGEMENT FOR PATIENTS WITH HIV INFECTION IN IKI ISLAND}

\author{
Yoshiaki UtSUnOMIYA ${ }^{1,2}$, KAZUNORI OiShI ${ }^{2}$, TSUYOSHI NAGATAKE ${ }^{2}$ AND \\ Keizo Matsumoto ${ }^{2}$ \\ Internal Medicine, Iki Public Hospital ${ }^{1}$ and \\ Department of Internal Medicine, Institute of Tropical Medicine, \\ Nagasaki University ${ }^{2}$
}

We discuss the marginal capacity and the possibility of the medical care and management for patients with $\mathrm{HIV}$ infection in the isolated island Iki through our experiences in Iki Public Hospital. The Iki island is located in Genkai-nada, the northern sae of Kyushu. The size of the island is $18 \mathrm{~km}$ north and south, $13 \mathrm{~km}$ east and west. The population is about 35,000 . We have had three male patients of hemophilia $\mathrm{A}$ infected with 
HIV. Case no.1 affected AIDS in 1987 and died in the following year due to opportunistic infections. At that time AIDS was incurable and prevention for this infection was not established, we accomplished terminal care for this patient without confusion and guarded his privacy. But in case no. 2 and 3 the relationship among patients and hospital staffs became worse after the responsible doctor for these patients moved. The patients were forced to visit a hospital in Fukuoka. With the joining of the new doctor to our hospital, the relationship among patients and staffs become good and better.

Followings are the unique difficulties in isolated islands on the present condition of medical care and management for patients with HIV infection were revealed through our experience. 1) The community of islands in a narrow closed area, there is disadvantage for patients with special disease such as HIV infection. 2) The hospital in islands is poorly equipped for the medical examination and treatment for HIV infection in general. 3) The medical staffs including doctors of the hospital in islands are inexperienced. 4) The condition of management of patients with HIV infection should be variable for better or worse by the responsible doctor. 5) It is difficult to secure capable and expert doctors everytime in isolated islands. 6) Transportation and information network get more advanced, more patients intend to visit a big hospital in a big city. On the other hand, we point out the following possibilities and assignment of medical care and management for patients with HIV infection in isolated islands. 1) We have demonstrated the appropriate care and management for HIV infected patients with enthusiasm. 2) We have to study the HIV infection and it's complications, and prepare to care and to manage the HIV infected patients including staffs, medicine and technique with simulation in a case of operation, delivery and emergency. 3) We expect mutual understanding among patients and medical staffs will be more developed by advance of transportation and information network.

\title{
112 CLINICAL STUDY ON RESPIRATORY INFECTION IN HIV-POSITIVE PATIENTS IN NORTHERN THAILAND
}

\author{
Hiroshi Watanabe ${ }^{1}$, Shinobu Kobayashi ${ }^{1}$, Kiwao Watanabe ${ }^{1}$,

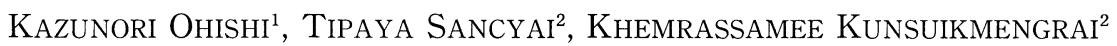 \\ Weerayut Kositsakulchai ${ }^{2}$, Sumpun Kahintapong ${ }^{2}$, Prasit Tharavichitkul ${ }^{3}$, \\ Thira Sirisanthana ${ }^{3}$ AND Tsuyoshi Nagatake ${ }^{1}$ \\ Department of Internal Medicine, \\ Institute of Tropical Medicine, Nagasaki University ${ }^{1}$, \\ Nakorn Ping Hospital ${ }^{2}$ and Faculty of Medicine, Chaing Mai University ${ }^{3}$
}

We studied the respiratory infection of $82 \mathrm{HIV}-$ positive patients (83 episodes, 51 males and 31 females, mean age 33.2 y.o.) in northern Thailand. Mean (CD4 (CD4/CD8) in 34 patients was $48.8 / \mathrm{mm}^{3}$ (0.08). Diagnosis were 49 pneumonia, 12 pulmonary mycobacteriosis, 10 Pneumocystis carinii pneumonia-like interstitial pneumonia, etc. Organisms detected from sputum were 12 Haemophilus influenzae, 8 Pseudomonas aeruginosa, 4 Rhodococcus equi, 3 Streptococcus pneumoniae, etc. And more than 2 organisms were detected from sputum and/ or blood in 9 cases $(10.8 \%)$.

Five Penicillium marneffei infection, 4 meningitis (cryptococcal 3 and tuberculous 1) and 2 septicemia (Staphylococcus aureus 1 and Pseudomonas spp. 1) occurred as severe complication, and 14 patients (16.9\%) were dead. In conclusion, there are a variety of organ isms and complications on respiratory infection in HIVpositive patients in northern Thailand. It is important to diagnose and treat early on the basis of our results. 


\title{
119 EXPRESSION OF CHEMOKINE RECEPTORS ON HUMAN CD4+ LYMPHOCYTES OF PERIPHERAL BLOOD FROM HIV-INFECTED INDIVIDUALS IN UGANDA
}

\author{
KazUnori Oishi ${ }^{1}$, Hiroyuki Yoshimine ${ }^{1}$, KazUShi Motomura ${ }^{1}$, \\ Atsushi Kumatori ${ }^{2}$ AND TSUYoshi NAGATAKE ${ }^{1}$ \\ Department of Internal Medicine ${ }^{1}$ and Department of Biochemistry ${ }^{2}$, \\ Institute of Tropical Medicine, Nagasaki University
}

To evaluate the expression of co-receptors for HIV1 , and to determine if a dynamic change in expression of CCR4 on CD4 lymphocyte, which has been shown to be Th2 cells, in African individuals, we developed a crosssectional study in which we examined the expression of CXCR4, CCR5, and CCR4 on CD + lymphocytes in the whole blood samples from HIV-1 infected and uninfected Ugandan adults by flowcytometry. We also examined the plasma viral load in HIV-infeceted individuals. We demonstrated the up-regulation of CCR5 and CCR4 expression, but there was no down-regulation of CXCR4 expression on CD4+ lymphocytes in the peripheral blood from African adults with HIV-1 advancing disease.
Plasma HIV-1 viremia significantly correlated with the percent $\mathrm{CD} 4$ on lymphocytes, but did not correlate with the degree of CCR5 and CCR4 expression on CD4+ lymphocytes in the peripheral blood from HIV-1 infected individuals. A lack of down-regulation of CXCR4 expression on CD4 lymphocytes may be due to immune activation in African individuals, and the up-regulation of CCR4 expression on CD4 lymphocytes may indicate a polarized type 2 state in HIV advancing disease (Collaborators: Masashi Hayano, Kouji Matsushima. Department of Molecular Preventive Medicine, School of Medicine, University of Tokyo. Peter Mugenyi. Joint Clinical Research Center, Uganda).

\section{EPIDEMIOLOGICAL PROPOSAL FROM U.S.A. FOR TB PROPHYLAXIS TO HIV-INFECTED PATIENTS IN THAILAND}

\author{
YASUYUKi RAKue ${ }^{1}$, Scott F. MicheaL ${ }^{1}$, ORASA SuthiEnKLE ${ }^{2}$ AND \\ PRAYONG RADOMYS ${ }^{2}$ \\ Department of Tropical Medicine, Tulane Medical Center, \\ SPH \& TM, LA., U.S.A. ${ }^{1}$ and \\ Mahidor University Bangkok, Thailand ${ }^{2}$
}

Tuberculosis represents one of the leading opportunistic infections in HIV-infected patients in developing countries. The close relationship between HIV infection and clinical tuberculosis has widely observed. The progression of recent TB incidence is now climbing alarmingly. By preventing tuberculosis will also help to reduce transmission of tuberculosis in Thailand. I propose to examine the impact of TB chemorprophylaxis for patients who are HIV-infected with positive tuberculin skin tests (TST + ) in Thailand.

[Study Design] Prospective, randomized, placebocontrolled, unmasked trial

To compare 3 arms: Isoniazid $300 \mathrm{mg}$ PO QD+Vitamin B6 $25 \mathrm{mg}$ PO QD $\times 6$ months

Rifampin $600 \mathrm{mg}$ PO QD+Ethambutol 1,500 mg PO $\mathrm{QD} \times 2$ months

[Inclusion Criteria] HIV seropositive (2 HIV-1 EIA or
1 HIV-1 EIA followed by Western blot), Chest X-ray with no evidence of active TB

[Exclusion Criteria Study Population] Active tuberculosis (pulmonary or extrapulmonary)

Prior TB chemoprophylaxis

[Sample Size] Baseline incidence of $\mathrm{TB}$ in $\mathrm{HIV}+$ untreated patients of $8 \%$ per person per year, Screen 1,500 HIV-infected patients followed in Mahidol University Hospital infectious disease clinics in Bangkok with tuberculin skin testing

[Sample Size Calculation Analysis] $\mathrm{p}_{1}=$ proportion of patients in placebo group who develop $=\mathrm{TB}$ 0.08. $\mathrm{p}_{2}=$ proportion of patients in treatment group who develop $\mathrm{TB}=0.02$

[Conclusion] The proportion of these developing active $\mathrm{TB}$ is statistically smaller in the group getting prophylaxis than in the group getting placebo. 


\title{
121 INTERNATIONAL ASSISTANCE TO DEVELOPMENT OF COMMUNITY-BASED TB PROGRAM BY NGO, -EXPERIENCE OF BRAC IN RURAL BANGLADESH
}

\author{
Akramul Islam ${ }^{1}$, Nobukatsu Ishikawa ${ }^{2}$, Susumu Wakai ${ }^{1}$ and Yasuhide Nakamura ${ }^{1}$ \\ The University of Tokyo ${ }^{1}$ and \\ The Research Institute of Tuberculosis, Japan Anti-Tuberculosis Association ${ }^{2}$
}

[Aim] Tuberculosis remains a major public health problem in Bangladesh, despite the efforts of the government program. We aim to discuss the role of NGOs and international assistance for successful TB program. [Methodology] The experience of Bangladesh Rural Advancement Committee (BRAC), one of the biggest NGOs for community development in Bangladesh is reviewed.

[Results and Discussion] BRAC started a pilot community based tuberculosis program in 1984. It covered a rural sub-district (thana) with 220,000 population, where about 200 community health workers (CHWs) were involved in educating community, identifying symptomatic patients, giving them anti-TB drugs until cure. Currently this model has been extended to 60 thanas, covering 14.6 million population in collaboration with the new government TB program. From January
1995 to June 1998, 13,014 patients were diagnosed, and $5,076(86.3 \%)$ out of 5,882 new sputum positive patients by June 1997 were cured by CHWs. This program has been supported financially by various international agencies such as DFID (UK), SIDA, SDC and UNICEF. The Research Institute of Tuberculosis (RIT) of Japan has made technical guidance and support, which is crucial for the success of the program. WHO also provides support through the government. Involving the community development NGOs like BRAC for the national TB program is proved to be effective. International assistance to this kind of approach is essential in developing countries.

[Conclusion] International resources both financial and technical need to be mobilized more towards community based NGOs for TB control.

\section{CHARACTERISTIC FINDINGS OF THE LIVER DISEASES IN NORTHERN THAILAND}

\author{
Kan Toriyama, Masachika IsEKI ANd Hideyo Itakura \\ Department of Pathology, \\ Institute of Tropical Medicine, Nagasaki University
}

We have performed a hospital-based histopathologic and virologic study of the liver diseases in northern Thailand. The most common liver disease among 275 biopsy cases is hepatocellular carcinoma (HCC;62), followed by chronic viral hepatitis $(\mathrm{CH} ; 36)$, cholangiocellular carcinoma (CCC;34), penicilliosis (21), fatty metamorphosis (13), adenocarcinoma with unknown primary site (12), ascending cholangitis (12), metastatic adenocarcinoma (11) and others. Comparing with the situation of the liver diseases in Japan, CCC showed a high incidence peculiarly and Opisthorchis viverrini infection, which is related to the life styles of the inhabitants in this area, is supposed to play a major role in CCC.

The dominant causative virus in $\mathrm{HCC}$ cases is $\mathrm{HBV}$
(81\%), followed by non-B, non-C virus (NBNCV;11\%) and $\mathrm{HCV}(8 \%)$. Among $\mathrm{CH}$ cases, $\mathrm{HBV}$ showed the highest prevalence (52\%), followed by $\mathrm{HCV}(29 \%)$ and NBNCV (19\%). It is well known that northern Thailand has witnessed an explosive rise in the number of HIV infected populations. The most common and characteristic hepatic manifestation of the opportunistic infections among HIV infected individuals is penicilliosis, caused by Penicillium marneffei. In addition, several liver diseases such as opportunistic infections, ascending cholangitis, cholelithiasis, intrahepatic cholestasis and alcoholic liver damage are suggested to be related to the geographical situation, socio-economic and hygienic conditions, and cultural practice in northern Thailand. 


\title{
123 AN IMPORTED CASE OF BRUCELLOSIS
}

\author{
YASUYuki Kato ${ }^{1}$, Gota Masuda ${ }^{1}$, IChiro Itoda ${ }^{1}$, Fumiaki Imamura ${ }^{1}$, \\ Atsushi Ajisawa ${ }^{1}$, Masayoshi Negishi ${ }^{1}$ and Morio KoIKE ${ }^{2}$ \\ Department of Infectious Diseases ${ }^{1}$ and Department of Pathology ${ }^{2}$, \\ Tokyo Metropolitan Komagome Hospital
}

A 64-year old Japanese man was admitted to our hospital with one-month-history of fever and low back pain. He had been good in health and visited Baghdad, Iraq three months before. He was given cephalosporins with no improvement. Careful questioning revealed that he had eaten sheep's milk cheese in Iraq. At the time of admission, his temperature was $38^{\circ} \mathrm{C}$. Examination revealed hepatosplenomegaly and spinal tenderness. Laboratory studies revealed a WBC count of $8,400 / \mu l$ and the erythrocyte sedimentation rate of $67 \mathrm{~mm} / \mathrm{h}$. Levels of hepatic enzymes were raised. Chest X-ray film was normal. A lumber puncture was performed. The CSF had normal levels of glucose and protein concentration, but lymphocytic pleocytosis was present. Brucella agglutinin titer was 1:800, and cultures of blood and intervertebral disk subsequently yielded $B$. melitensis. Biopsy specimens of the liver revealed noncaseating granuloma and mononuclear cell infiltraton.

A magnetic resonance imaging revealed diffuse high signal intensity of the L3-L5 vertebrae and a paraspinal mass at this level, which were thought to represent vertebral osteomyelitis and epidural abscess, respectively. Treatment with doxycycline, rifampicin and streptmycin for four weeks resulted clinical improvement. This was followed by rifampicin, trimethoprim-sulfamethoxazole and tosfloxacin for a total of five months. His wife who did not visit Iraq with him developed fever one month later. Cultures of her blood also yielded $B$. melitensis. The organism was thought to transmit from him to his wife.

\section{HAULAGE METHODS AND DIUNAL HABITS OF THE PORTERS IN KATHMANDU}

\author{
Eiko Kaneda And Mitsuo Kosaka \\ Department of Environmental Physiology, \\ Institute of Tropical Medicine, Nagasaki University
}

The mountainous nature of most of Nepal restricts the development of vehicular transportation. People have to depend on human power even today, especially porters who use a number of different transport styles.

The aim of this study were to document (1) the characteristics of haulage methods in relation to the geographical conditions, and (2) the diurnal activities and health of porters in Kathmandu.

First, according to the geographical features two places were selected for each of the three different geographical areas: Terai zone, Mountain zone and Himalayan zone. In each of these places, observations were made on the tribes of the porters and on the techniques employed for carrying their loads. As the result, the porters in Nepal to carry loads were divided into four main classes: (1) in baskets on a yoke across the shoulders, (2) by handcart, (3) on the top of the head, and (4) on the back using a rope. The method of carrying a load on the back with a rope was most commonly observed, although this style might cause damage to the spinal vertebrae.

Secondly, the study of the diurnal activities and health condition of porters was limited to those in Kathmandu. For this purpose seven porters were interviewed orally. The results can be summarised as follows: (1) luggage of about $60 \mathrm{~kg}$ to $110 \mathrm{~kg}$ could be carried, (2) six of the seven porters habitually smoked tobacco and drank alcohol, (3) many porters wore cloth tightly twisted around their waist, and (4) complaints of severe neck pain were not made, but all porters complained of knee and/or back pains.

On the other hand, X-ray photographs of the cervical and lumbar spine regions of the porters were taken to investigate possible changes in the vertebrae. The ratio of the front length to the back length for each vertebral body was calculated and compared. However, $\mathrm{X}$-ray examination showed no significant differences $(P>0.05)$ in the vertebral bodies of either the cervical or the lumbar regions of the porters examined in this study. This appears to be because the muscles support- 
ing their cervical vertebrae were very well trained and developed. Even if there were some unobserved degenerative changes in the spines of these porters, it would be difficult to prove a causal relationship between occu- pation and injury, because cervical spondylosis and degenerative intervertebral disks also occur with ageing.

\title{
126 INTERNATIONAL COLLABORATION DURING THE EPIDEMIC ENCEPHALITIS OUTBREAK IN MALAYSIA, 1999
}

\author{
KOUICHI MORITA AND AKIRA IGARASHI \\ Department of Virology, Institute of Tropical Medicine, \\ Nagasaki University
}

\begin{abstract}
[Background] An epidemic encephalitis outbreak occurred in northern part of Peninsular Malaysia, Japanese encephalitis (JE) endemic area, since late 1998. Epidemic area expanded to southern part of the peninsular by February in 1999 and disease intervention activities for JE was strengthened in the affected areas. However, the number of patients increased in March. In middle of March, a novel virus was isolated in University of Malaya from cerebro-spinal fluids of patients and soon identified as Hendra-like virus by CDC in the USA. The virus was confirmed as the pathogen and named Nipah virus after the name of village of the patients. Swine in the farm were considered as source of pathogen to the humans and the government immediately started nation-wide destruction of pigs in the infected areas. Under these circumstances, the authors were dispatched to the country by JICA in order to collaborate in the disease control programme in middle of April 1999.

[Purpose] The purpose of the visit was to overview the situation of the epidemic encephalitis possibly due to Nipah virus and JE virus and to make recommendations for control of the diseases.

[Method] The authors made a visit to the epidemic
\end{abstract}

areas, Malaya University, Ministry of Health and a governmental reference laboratory for JE laboratory diagnosis in IMR (Institute for Medical Research) in Kuala Lumpur.

[Findings] Nipah virus encephalitis cannot be distinguished from Japanese encephalitis by clinical manifestations and other clinical laboratory data. However, epidemiological features were clearly distinct for each diseases due to different mode of transmission (JE: mosquito-borne, Nipah: direct contact). Authors confirmed JE cases among the patients during December 1998 as diagnosed by IgM-Capture ELISA. On the contrary, most of the patients after February 1999 were considered not JE. These patients were diagnosed as Hendra-like virus infection by CDC team. The epidemic was completely contained after the government destroyed nearly one million pigs by the end of April, 1999. Reservoir of the virus in nature is not yet clear.

[Discussion] Foreign research institutions, particularly $\mathrm{CDC}$, played a key role in virus identification and disease surveillance during emergency situation: Relevant institutions in Japan should strengthen suitable capacity to respond to emerging infectious disease outbreaks at an international level.

\section{IMMUNOLOGICAL INVESTIGATIONS ON DIARRHEAL DISEASES CONTROL OF CHILDREN IN DEVEROPING COUNTRIES}

\author{
TAKASHI NAKAnO ${ }^{1}$, Hitoshi KAmiYA ${ }^{1}$ AND B.D. AKANMORI ${ }^{2}$ \\ Department of Pediatrics, National Mie Hopital ${ }^{1}$ and \\ Noguchi Memorial Institute for Medical Research, Ghana ${ }^{2}$
}

Diarrhoea is one of the most serious diseases burdens of children in developing countries. Infective agents, host immunity, nutritional status interact one another. We investigated and analysed these factors to establish effective control measures for diarrhoeal diseases. 
A prospective study was carried out in an urban slum, Nima-Maanobi near Accra, the capital city of Ghana from 1996-1998. The target population were under 3 years old and 601 children were recruited. Diarrhoea occurred to 355 cases (59\%), but 246 (41\%) didn't have diarrhoea. Acute diarrhoea accounted 460 epiosodes (83\%) and 97 (17\%) were persistent diarrhoea which lasted more than 14 days. Acute diarrhoea had its peak of occurrence between 7 and 12 months old, and persistent diarrhoea occurred frequently in younger (4-6 months old) infants.

Microbiological investigations were performed for acute diarrhoea, persistant diarrhoea, and healthy children. No particular agent was isolated with a significantly high rate from acute and persistent diarrhoeal cases. The causative candidates for persistent diarrhoea such as enteroaggregative $E$. coli, Cryptosporidium,
Giardia lamblia were not isolated significantly high from persistent diarrhoea group.

Surface marker analysis of lymphocytes indicated that $\mathrm{CD}_{1} 9^{+}$cells, $\mathrm{CD} 4 / 8$ ratio, $\mathrm{CD}_{16}{ }^{+} / 56^{+}$cells were decreased in persistent diarrhoea group compared with acute diarrhoea group. Malnourished children also had decreased number of the same subpopulation of lymphocytes. Analysis of blood samples from healthy Ghanaian children revealed that $\gamma \delta \mathrm{T}$ cells were increased.

These observations can become an introduction to clarify immunological backgrounds of severe or intractable diarrhoea. We should aim at persistent diarrhoea, and study for virulence facors and host factors on each case. These examinations will be beneficial for establishing more effective strategies of diarrhoea diseases control.

\title{
129 PROCESS OF SETTING UP HAEMOPHILUS INFLUENZAE TYPE B (HIB) VACCINATION PROJECT FOR BANGLADESHI CHILDREN TO TREVENT MENINGITIS
}

\author{
Hironori MASAKI ${ }^{1}$, NaOto Rikitomi ${ }^{1}$, K. Ahmed ${ }^{1}$, KiWao WATANABE ${ }^{1}$, \\ KazUnori Oishi ${ }^{1}$, TsuYoshi Nagatake ${ }^{1}$, Keizo Matsumoto ${ }^{1}$, S.K. Saha ${ }^{2}$,

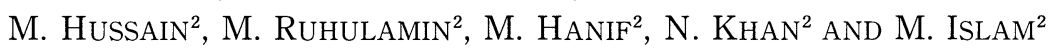 \\ Department of Internal Medicine, \\ Institute of Tropical Medicine, Nagasaki University ${ }^{1}$ and \\ Dhaka Shishu (Children) Hospital, Bangladesh ${ }^{2}$
}

Haemophilus influenzae Type b (Hib) is the most important pathogen in acute purulent meningitis. In our previous study, it was demonstrated that one-third of these patients die. In developing countries, the effectiveness of Hib vaccine for both children and adults has not yet been fully evaluated. We report here the process of setting up of Hib vaccine project for Bangladeshi children. The aim of the Hib vaccine project is to improve child health in developing countries.

[Setting] Kaligonj in Gazipur district, located at about $40 \mathrm{~km}$ from Dhaka city, Bangladesh.

[Materials and Methods] Hib vaccine will be given for about 1,000 children, under 5 years old (mainly 2 years old), utilizing government thana health center in
Kaligonj. Expanded programme of immunization (EPI) is still working there. Therefore running cost for vaccination and its follow-up study will not be high. Hib vaccine will be purchased by donation from Rotary Club of Nagasaki, Rotary Club of Dhaka, and International Rotary Club. Follow-up study of Hib vaccine will be supported by Japan International Cooperation Agency (JICA). During the study period, patients with severe illness will be transported to Dhaka Shishu (Children) Hospital for further examination and treatment.

[Results and Conclusion] Hib vaccine project will be initiated from April, 2000. We are looking forward for further collaboration with persons who are interested in our project. 


\title{
130 FOOD PLANT-BASED VACCINES AGAINST INFECTIOUS DISEASES
}

\author{
TAKeshi ARakawa And Yoshiya Sato \\ Department of Parasitology, Faculty of Medicine, University of the Ryukyus
}

A gene encoding the cholera toxin B subunit (CTB), fused to an endoplasmic reticulum retention signal (SEKDEL), was inserted adjacent to the bi-directional mannopine synthase $\mathrm{P} 2$ promoter in a plant expression vector containing a bacterial luciferase marker gene linked to the P1 promoter. Potato plants were transformed by Agrobacterium tumefaciens carrying the vector and kanamycin-resistant plants were regenerated. The CTB-SEKDEL fusion gene was identified in the genomic DNA of bioluminescent plants by polymerase chain reaction amplification. Immunoblot analysis indicated that plant-derived CTB was antigenically indistinguishable from bacterial $\mathrm{CTB}$, and that pentameric CTB molecules $\left(\mathrm{M}_{\mathrm{r}} \sim 50 \mathrm{kDa}\right)$ were the dominant molecular species isolated from transgenic potato tissues. The maximum amount of CTB was approximately $0.3 \%$ of total soluble plant protein. Enzyme-linked immunosorbent assay indicated that plant-synthesized CTB bound specifically to $\mathrm{G}_{\mathrm{M} 1}$-ganglioside, the natural membrane receptor of cholera toxin (CT). In the presence of the SEKDEL signal, CTB accumulates in potato tissues and is assembled into an pentameric form which retains native biochemical and immunological properties.

Feeding transgenic potato tissues to mice induced both serum and intestinal anti-CTB antibodies. Mucosal antibody titers declined gradually after the last oral immunization but were restored following an oral booster of transgenic potato tissues. Following intraileal injection with CT, the plant-immunized mice showed up to a $60 \%$ reduction in diarrheal fluid accumulation in the small intestine. Protection against CT was based on inhibition of enterotoxin binding to the cell surface receptor $\mathrm{G}_{\mathrm{M} 1}$-ganglioside. The experimental results demonstrate the ability of transgenic food plants to generate protective immunity in mice against a bacterial enterotoxin, which may open the way for development of food plants as production and delivery systems for mucosal immunization.

\section{DEPRESSION OF IMMUNOLOGICAL ABILITY BY ULTRAVIOLET RAYS AND PROTECTION FROM ULTRAVIOLET RAYS}

\author{
Nobu Ohwatari, Yu CaO, Eiko Kaneda and Mitsuo Kosaka \\ Department of Environmental Physiology, \\ Institute of Tropical Medicine, Nagasaki University
}

Exposure to ultraviolet rays (UV) influences on ability of immunity, and induces tissue degeneration. Furthermore, long term exposure of UV causes skin cancer. Immunity has important role to protect against infectious disease, so we investigated relationship of dose responses of $\mathrm{UV}-\mathrm{B}$ and ratio of $\mathrm{CD} 4$ to $\mathrm{CD} 8$. Additionally, protections from UV in wild mammals is shown in this study.

Whole body of mouse (DDY mouse, $\mathrm{N}=16$ ) were irradiated UV-B of $0 \mathrm{~J} / \mathrm{m}^{2}$ (Control), $40 \mathrm{~J} / \mathrm{m}^{2}, 400 \mathrm{~J} / \mathrm{m}^{2}$, $2,000 \mathrm{~J} / \mathrm{m}^{2}$ at two times with one week interval. $\mathrm{CD} 4$ and $\mathrm{CD} 8$ measured on 3, 7, 14 days after the second UV$\mathrm{B}$ irradiation with $100 \mu l$ of heart drawing blood. On irradiation at $400 \mathrm{~J} / \mathrm{m}^{2}, \mathrm{CD} 4 / \mathrm{CD} 8$ decreased $3.42 \pm 0.28$ to $2.05 \pm 0.18$ on 7 th day after the last irradiation, which was small on indvidual deference in mice and was lowest compared with other irradiation mice. The $400 \mathrm{~J} / \mathrm{m}^{2}$ of UV-B was equal to exposure by solar energy for $2 \mathrm{~min}$ and $32 \mathrm{sec}$ at 12 o'clock in May in Nagasaki City.

On protections from the ultraviolet rays in wild mammals, the study used Yellow rats $(\mathrm{N}=9)$, Squirrels $(\mathrm{N}=12)$, Jirds $(\mathrm{N}=15)$ and Pikas $(\mathrm{N}=17)$ with black layers, and Wistar rats $(\mathrm{N}=12)$ for controls. Wild mammals has a two color structure. It is black near the body, and is body color the end. The black part of the hair (black layer) may be effective in absorbing UV.

1) Transmittance of UV through the black layer is significant low compared with rats, because of black layer absorbed UV efficiently. So, the black layer has an effective role to protect the skin tissue from UV.

2 ) These wild mammals possess the protecting ability 
with black layer of hair and/or thick epidermis to protect skin from UV, and environmental conditions influence the protecting ability.

3 ) A little UV-B changed the ratio of $\mathrm{CD} 4 / \mathrm{CD} 8$ easily, therefore we must consider the influence of UV on infection in tropical zone in which human without long hair are exposed to severe UV irradiation. 